\title{
Early Oligodendrocyte/Myelin Pathology in Alzheimer's Disease Mice Constitutes a Novel Therapeutic Target
}

\author{
Maya K. Desai, ${ }^{\dagger \dagger}$ Michael A. Mastrangelo, ${ }^{\dagger}$ \\ Deborah A. Ryan, ${ }^{\dagger \ddagger}$ Kelly L. Sudol, ${ }^{\dagger}$ \\ Wade C. Narrow, ${ }^{\dagger}$ and William J. Bowers ${ }^{\star \dagger \S}$ बा \\ From the Departments of Pharmacology and Physiology," \\ Neurology, and Microbiology and Immunology, " the Center for \\ Neural Development and Disease, ${ }^{\dagger}$ and the Interdepartmental \\ Graduate Program in Neuroscience, ${ }^{\ddagger}$ University of Rochester \\ Medical Center, Rochester, New York
}

The detection of myelin disruptions in Alzheimer's disease (AD)-affected brain raises the possibility that oligodendrocytes undergo pathophysiological assault over the protracted course of this neurodegenerative disease. Oligodendrocyte compromise arising from direct toxic effects imparted by pathological amyloid- $\beta$ peptides and/or through signals derived from degenerating neurons could play an important role in the disease process. We previously demonstrated that $3 \times$ Tg-AD mice, which harbor the human amyloid precursor protein Swedish mutant transgene, presenilin knock-in mutation, and tau P301L mutant transgene, exhibit significant alterations in overall myelination patterns and oligodendrocyte status at time points preceding the appearance of amyloid and tau pathology. Herein, we demonstrate that $A \beta_{1-42}$ leads to increased caspase- 3 expression and apoptotic cell death of both nondifferentiated and differentiated mouse oligodendrocyte precursor (mOP) cells in vitro. Through use of a recombinant adeno-associated virus serotype-2 (rAAV2) vector expressing an $\mathbf{A} \beta_{1-42}$-specific intracellular antibody (intrabody), oligodendrocyte and myelin marker expression, as well as myelin integrity, were restored in the vector-infused brain regions of $3 \times \mathrm{Tg}$-AD mice. Overall, this work provides further insights into the impact of $A \beta_{1-42}$-mediated toxicity on the temporal and spatial progression of subtle myelin disruption during the early presymptomatic stages of $\mathrm{AD}$ and may help to validate new therapeutic options designed to avert these early impairments. (Am J Pathol 2010, 177:1422-1435; DOI: 10.2353/ajpath.2010.100087)
Alzheimer's disease (AD) is classically thought of as a gray matter disease; however, white matter lesions and pathology have been widely reported in the brains of incipient and mildly afflicted individuals. ${ }^{1-3}$ The underlying cause of the observed white matter changes in early $\mathrm{AD}$ brains may relate to compromised function of cells of the oligodendrocyte lineage resulting from disease-related insults. ${ }^{4,5}$ Initial AD-related white matter aberrations often precede advanced stages of $A D$ described by overt amyloid and tau pathology. 6,7 The inability of oligodendrocytes to sufficiently myelinate neuronal processes or maintain extant myelin status might render the affected axonal processes vulnerable to disease-related inflammation, oxidative stress, fibrillogenic $A \beta$, or phospho-tau species. ${ }^{4,5}$ Importantly, neuronal impulse conduction may be perturbed, thereby contributing to the signature $\mathrm{AD}$ symptoms such as memory loss and confusion. These initial white matter changes in the $A D$ brain may trigger a cascade of more advanced AD pathology and exacerbate the disease course. Therefore, it may be critical to develop strategies to circumvent these abnormalities in white matter during AD.

Previous studies in human AD patients have demonstrated that myelination in the brain occurs in a "heterochronological" pattern and AD pathology develops in a spatio-temporal manner, affecting the brain regions with most protracted course of myelination the earliest. ${ }^{8,9} \mathrm{We}$ demonstrated similar observations in triple transgenic $A D$ mice ( $3 \times \mathrm{Tg}-\mathrm{AD}$ ), a model genetically engineered to develop amyloid and tau-related pathologies in patterns and brain regions reminiscent of human $A D .^{5,10}$ $3 \times$ Tg-AD mice harbor three mutations: human presenilin-1 M146V (PS1 ${ }^{\mathrm{M} 146 \mathrm{~V}}$ ), human amyloid precursor protein Swedish mutation (APP ${ }^{\text {Swe }}$ ), and the P301L mutation of human tau (tau ${ }^{\mathrm{P} 301 \mathrm{~L}}$ ) and display white matter disruption and alteration in myelin marker expression in subre-

\footnotetext{
Supported by T32-NS051152 (M.K.D.) and R01-AG026328 (W.J.B.). Accepted for publication May 20, 2010.

Address reprint requests to William J. Bowers, Ph.D., Department of Neurology, Center for Neural Development and Disease, University of Rochester Medical Center, 601 Elmwood Avenue, Box 645, Rochester, NY 14642. E-mail: william_bowers@urmc.rochester.edu.
} 
gions of the hippocampus and the entorhinal cortex brain regions as early as 2 months of age. ${ }^{5}$ These mice exhibit signs of intracellular $A \beta$ peptide accumulation and cognitive impairment as early as 3-4 months of age, while amyloid plaque and tangle pathology develop at more advanced ages (12-18 months). ${ }^{11,12}$ Collectively, these observations indicate that memory deficits and myelination changes in the $3 \times \mathrm{Tg}-\mathrm{AD}$ mice arise before the onset of overt amyloid and tau pathology, thus implicating early disease-related signaling in these abnormalities. ${ }^{11}$

The underlying causes of oligodendrocyte and myelin dysfunction in AD have not been fully clarified. Increased levels of $A \beta$ peptides have been correlated previously with brain regions exhibiting myelin abnormalities in human AD patients. ${ }^{4}$ Similarly, pathological characterization of $3 \times \mathrm{Tg}-\mathrm{AD}$ mice revealed immunohistochemically detectable intracellular $A \beta_{1-42}$ at ages and in regions comparable to the appearance of myelin and oligodendrocyte disruption. ${ }^{11}$ Previously reported in vitro studies have illustrated toxicity induced by various forms of $A \beta$ peptides on oligodendrocytes. ${ }^{13-15}$ Collectively, these correlative observations identify $A \beta$ peptide species as potential triggers of myelin and oligodendrocyte deficits in $A D$. In the present study, we sought to more directly examine the effects of $A \beta_{1-42}$ in the $3 \times \mathrm{Tg}-\mathrm{AD}$ mouse model by using a previously engineered intrabody (IB) targeted specifically against $A \beta_{1-42}$. This IB was stereotactically delivered and chronically expressed in vivo via a viral vector to further implicate $A \beta_{1-42}$ peptide species in the age-related degradation of myelin and oligodendrocyte status. Herein, using biochemical, immunohistochemical, and ultrastructural analyses, we report that $\mathrm{A} \beta_{1-42}$-incited mechanisms undermine the oligodendrocyte lineage in vitro and in $3 \times \mathrm{Tg}-\mathrm{AD}$ mice. Moreover, these pathological signals can be suspended by blocking parenchymal $A \beta_{1-42}$ accumulation at an early stage of disease. In aggregate, our results further highlight $A \beta_{1-42}$ as a viable target for early $A D$ intervention strategies and that its selective blocking via passive immunotherapeutics can delay or even prevent the elaboration of $A D$ related white matter pathology.

\section{Materials and Methods}

\section{Mouse Oligodendrocyte Precursor ( $\mathrm{mOP}$ ) Cell Line}

The mOP cell line was developed and kindly provided by Dr. Steven A. Reeves (Massachusetts General Hospital, Charlestown, MA). ${ }^{16}$ The cell line was maintained in the mOP proliferation medium (PM) as previously described. ${ }^{16}$ The PM medium consists of $10 \mu \mathrm{g} / \mathrm{ml}$ biotin, $5 \mu \mathrm{l} / \mathrm{ml} \mathrm{N} 1$ supplement, $5 \mu \mathrm{g} / \mathrm{ml}$ insulin (Sigma, St. Louis, MO), 70\% high glucose DMEM, and 30\% B104 neuroblastoma cell line conditioned medium. Differentiation medium, consisting of all components of PM except insulin and N1 supplement, was used to induce differentiation of $\mathrm{mOP}$ cells. For $A \beta$ peptide treatment of nondifferentiated mOP cells, cells were plated in PM for 2 days, followed by $A \beta$ peptide addition. Complementing studies in differenti- ated $\mathrm{mOP}$ cells were performed by culturing $\mathrm{mOP}$ cells in PM for 3 days and then in differentiation medium for 2 more days, followed by exposure to $A \beta$ peptides.

\section{$A \beta$ Peptide Treatment}

$\mathrm{A} \beta_{1-42}$ or $\mathrm{A} \beta_{42-1}$ peptides (American Peptide, Sunnyvale, $\mathrm{CA}$ ) were diluted to a $1 \mathrm{mmol} / \mathrm{L}$ stock concentration in $\mathrm{dd}_{2} \mathrm{O}$ and stored at $-20^{\circ} \mathrm{C}$. Nondifferentiated and differentiated $\mathrm{mOP}$ cells were treated with a final concentration of $0.25,0.50,1.00,2.00,4.00 \mu \mathrm{mol} / \mathrm{L} \mathrm{A} \beta_{1-42}$ or $\mathrm{A} \beta_{42-1}$ peptide and incubated at $37^{\circ} \mathrm{C}, 6 \% \mathrm{CO}_{2}$ for 4 hours. The mOP cells were then fixed using $4 \%(\mathrm{w} / \mathrm{v})$ paraformaldehyde, washed, and stored in phosphate buffered saline (PBS) at $4^{\circ} \mathrm{C}$ until staining was performed.

\section{In Vitro Immunocytochemistry and Hoechst Staining}

Fixed mOP cells were permeabilized in $0.1 \%$ Triton-X100 in PBS, blocked in $10 \%$ goat serum in PBS, and incubated in primary antibodies for 2', 3'-cyclic nucleotide 3'-phosphodiesterase (CNPase) and myelin basic protein (MBP; 1:1000 and 1:200, respectively; Chemicon International, Billerica, MA). The cells were then washed and stained with Alexa Fluor goat anti-mouse 568 and goat anti-rat 488 secondary antibody (1:2000, Molecular Probes, Carlsbad, CA). The cells were washed and coverslips were mounted on glass slides using Mowiol aqueous mounting media.

Active caspase-3 and myc staining was performed similarly using 3,3'-Diaminobenzidine (DAB) staining. The cells were incubated in primary antibody for active caspase-3 (1:600, Promega, San Luis Obispo, CA) or c-myc, clone $9 \mathrm{E} 10$ (1:1000, Sigma), washed in PBS, and then incubated in biotinylated goat anti-rabbit immunoglobulin (1:2000, Rockland Immunochemicals, Gilbertsville, PA). Cells were washed with PBS, the HRP activity conjugated, and the antigen-antibody complexes were subsequently developed using a DAB peroxidase kit (Vector Laboratories, Burlingame, CA). Hoechst staining was performed by incubating the fixed $\mathrm{mOP}$ cells in 1 $\mu \mathrm{mol} / \mathrm{L}$ Hoechst 33342 dye (Sigma). Cells were subsequently washed and imaged. Stained cells were analyzed using an Olympus DP71 microscope equipped with a motorized stage (Olympus, Melville, NY), and images were captured under $\times 20$ magnification for all stains.

\section{Apoptosis Quantification}

Four fields were randomly sampled from each well by microscopy for cells stained with Hoechst 33342, and the total numbers of cells was determined for each condition. The number of pyknotic cells with condensed or fragmented nuclei was summated in the sampled regions, and the percentage of pyknotic cells per coverslip was subsequently calculated. Similarly, for active caspase-3 staining the total numbers of cells and active caspase3-positive cells were calculated in randomly sampled 
regions, and the percentages of positive cells were determined.

\section{Mouse Strains}

Triple-transgenic Alzheimer's disease $(3 \times$ Tg-AD) mice were generated on the 129/C57BL/6 background as previously described and were kindly provided by Dr. Frank LaFerla. ${ }^{10,17}$ Age-matched 129/C57BL/6 mice or C57BL/6 mice were used as non-transgenic (Non-Tg) controls where indicated. Age-matched male mice were used for all experiments ( $N=6$ per experimental group for immunocytochemical studies, $N=3$ per experimental group for electron microscopy and biochemical assays). All animal housing and procedures were performed in compliance with guidelines established by the University Committee of Animal Resources at the University of Rochester.

\section{Brain Homogenates}

Entorhinal cortex from $3 \times \mathrm{Tg}-\mathrm{AD}$ and C57BL/6 mice at 2 and 6 months of age were microdissected and frozen at $-80^{\circ} \mathrm{C}$ until ready for use. Frozen tissue was weighed, then homogenized in 1\% SDS, 0.1\% Tween-20 in PBS with a protease inhibitor cocktail (Sigma) at a 1:10 weight: volume ratio. It was subsequently ultra-centrifuged at $100,000 \times g$ for 1 hour at $4^{\circ} \mathrm{C}$. Supernatants were removed to a new tube and assayed for protein concentration. Based on protein assay results samples were diluted to the same final concentration of $4 \mathrm{mg} / \mathrm{ml}$.

\section{Western Blotting for Human $A \beta_{1-42}$}

Entorhinal cortex homogenates were analyzed via sodium dodecyl sulfate polyacrylamide gel electrophoresis (SDS-PAGE) using 12\% Tris-Glycine gels. Homogenates were combined with sample buffer containing 2-mercaptoethanol, and boiled for 5 minutes. One hundred micrograms of total protein was loaded onto gels along with SeeBlue Plus2 (Invitrogen, Carlsbad, CA) prestained molecular weight markers. Each lane of the gel represents a different mouse. Protein samples were electrophoretically separated at $100 \mathrm{~V}$ then transferred to polyvinylidene difluoride membranes at $4^{\circ} \mathrm{C}$ for 1 hour at 300 mAmps. Polyvinylidene difluoride membranes were blocked for 1 hour at room temperature $\left(\sim 22^{\circ} \mathrm{C}\right)$ in Tris-buffered saline with $0.1 \%$ Tween-20 (TBST) and 5\% nonfat dried milk. Membranes were then incubated with the 12F4 anti-A $\beta 42$ (Covance, Berkeley, CA) at a 1:1000 dilution overnight at $4^{\circ} \mathrm{C}$ and washed $4 \times 5$ minutes with TBST. A horseradish peroxidase-conjugated secondary antibody was used at a 1:2000 dilution for 1 hour at room temperature, washed as above, then washed $1 \times 5$ minutes in TBS. Immunopositive $A \beta$ species were visualized using chemiluminescence (Western Lightning Reagent, PerkinElmer, Waltham, MA). The membrane was stripped and reprobed with anti- $\beta$-actin (1:5000, Sigma) to ensure equal loading.

\section{Dot Blot}

Entorhinal cortex homogenates were spotted onto nitrocellulose membranes while vacuum pressure was applied. Each dot consisted of $12 \mu \mathrm{g}$ of total protein. Membranes were allowed to dry before immunoblotting was performed. Membranes were blocked for 1 hour at room temperature in TBST and 5\% nonfat dried milk. Membranes were subsequently blotted using primary antibody I11, an oligomer-specific antibody (provided by Dr. Charles G. Glabe, UC Irvine), at 1:2000 dilution overnight at $4^{\circ} \mathrm{C}$ and washed $4 \times 5$ minutes with TBST. A horseradish peroxidase-conjugated secondary antibody was used at a 1:2000 dilution for 1 hour at room temperature, washed as above, then washed $1 \times 5$ minutes in TBS. The membrane was stripped and reprobed with anti- $\beta$-actin (1:5000) to normalize dots for total protein level. Dot blots were visualized with chemiluminescence and analyzed for total raw density (Labworks by UVP, Upland, CA).

\section{Construction, Verification, and Packaging of IB-Expressing rAAV Vectors}

The construction of the pAAV-scFvA $\beta_{\mathrm{KDEL}}{ }^{\mathrm{IB}}$ vector, which expresses an endoplasmic reticulum (ER)-targeted anti$A \beta 42$ specific IB, was previously described. ${ }^{18}$ We similarly constructed a control vector (parent scFv construct kindly provided by Dr. Mark A. Sullivan, University of Rochester), ${ }^{19}$ which expresses an ER-targeted anti-phenobarbital-specific single-chain IB (pAAV-scFvphe ${ }_{K D E L}{ }^{I B}$ ). Briefly, a phenobarbital-specific IB sequence with an in-frame ER targeting signal (KDEL) and c-myc epitope tag at the $\mathrm{C}$ terminus to facilitate immunocytochemical detection was cloned into the pBS-FBR ${ }_{\text {mcs }}$ shuttle vector under the transcriptional control of the human cytomegalovirus promoter and a SV40-derived polyadenylation signal was included at the $3^{\prime}$ end of the transcription unit. This transcription unit was excised and cloned into the inverted terminal repeatcontaining parent plasmid, pFBGR. Subsequently, baby hamster kidney cells were plated on coverslips and transiently transfected with the pAAV-scFVA $\beta_{\mathrm{KDEL}}{ }^{\mathrm{IB}}$ and $\mathrm{PAAV}$ scFvphe $_{\mathrm{KDEL}}{ }^{\mathrm{IB}}$ plasmids, and immunocytochemistry was performed to verify IB expression in the cells. On verification, the pAAV-scFVA $\beta_{\mathrm{KDEL}}{ }^{\mathrm{IB}}$ and pAAV-scFvphe ${ }_{\mathrm{KDEL}}{ }^{\mathrm{IB}}$ plasmids were packaged into serotype-2 virions using a previously described baculovirus-based methodology. ${ }^{20}$

\section{Stereotactic Injections Using Convection Enhanced Delivery}

Recombinant AAV vectors were stereotactically delivered using convection-enhanced delivery method into 2-month-old male $3 \times \mathrm{Tg}-\mathrm{AD}$ mice and Non-Tg mice in accordance with approved University of Rochester animal use guidelines, as previously described with a few modifications. ${ }^{18}$ Briefly, mice were anesthetized with Avertin $(300 \mathrm{mg} / \mathrm{kg}$ ) and positioned in the stereotactic apparatus. The skulls of the mice were exposed, burr holes were drilled bilaterally over the designated hip- 
pocampal coordinates (Bregma, $-2.06 \mathrm{~mm}, 1.5 \mathrm{~mm}$ laterally, $-1.25 \mathrm{~mm}$ ventrally), and the injections were performed using an UltraMicro pump (WPI Instruments, Sarasota, FL) with a 33-gauge needle gradually inserted to the desired depth. A total volume of $5 \mu$ l of either

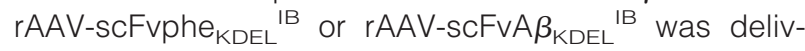
ered by a continuous injection via increasing delivery rates starting at $100 \mathrm{nl} / \mathrm{min}$ for 6 minutes, $200 \mathrm{nl} / \mathrm{min}$ for 10 minutes, and finishing at $400 \mathrm{nl} / \mathrm{min}$ for 6 minutes into both hemispheres. Following the completion of both injections, the incisions were closed using vicryl sutures, and topical $5 \%$ lidocaine ointment (Fougera, Melville, NY) was applied. The mice were then allowed to recuperate in a heated recovery chamber, transferred to their homing cage, and returned to the vivarium. The mice were sacrificed at 6 months of age and the brain tissue was harvested for immunocytochemistry, biochemical assays, and electron microscopy.

\section{Tissue Harvest and Processing}

Non-Tg control and $3 \times T$ Tg-AD mice were anesthetized with pentobarbital and perfused by transcardiac perfusion with $4 \%(\mathrm{w} / \mathrm{v})$ paraformaldehyde. Brains were removed and postfixed overnight in $4 \%$ paraformaldehyde at $4^{\circ} \mathrm{C}$ followed by sequential transfer in $20 \%$ sucrose in PBS overnight and 30\% sucrose in PBS until sectioned. Brains were sectioned coronally $(30 \mu \mathrm{m})$ on a sliding microtome and stored in cryoprotectant at $-20^{\circ} \mathrm{C}$ until processed for immunohistochemistry and black-gold myelin staining.

\section{Black-Gold II Myelin Staining and Quantification}

Non-Tg and $3 \times$ Tg-AD mouse brain tissue was stained for myelin using Black-Gold II myelin staining kit (Millipore, Temecula, CA) Briefly, tissue was mounted on glass slides, rehydrated, and myelin stained using $0.3 \%$ Black-Gold II. The stain was then fixed using $1 \%$ sodium thiosulfate, washed, dehydrated, and sealed using mounting medium (Richard-Allan Scientific, Hudson, $\mathrm{NH}$ ) with coverslips. Staining was visualized using an Olympus AX-70 microscope and $\times 20$ images were captured. Investigator-blinded quantitative analysis of images was performed using the MCID software program (InterFocus Imaging Ltd., Cambridge, UK). The analysis was done by first setting a target intensity threshold and assessing total target pixels meeting the threshold criterion. The images were also assessed for the total number of myelinated fibers present in the given target area. Three consecutive sections for each mouse from both hemispheres within each group were analyzed. Pixel intensity was averaged across all images and mice within a group, and all statistics were analyzed using Prism GraphPad software (GraphPad Software, San Diego, CA).

\section{Immunohistochemical Detection and Analysis of Olig2, CC-1, CNPase, MBP, and Neurofilament}

Immunohistochemical analyses for CNPase and MBP (1: 1000 and 1:200, respectively) were performed on Non-Tg and $3 \times \mathrm{Tg}-\mathrm{AD}$ mouse brain tissue, as previously described. ${ }^{5}$ Briefly, sections were washed in phosphate buffer (PB) to remove the cryoprotectant and the tissue was mounted on glass slides, allowed to dry, and antigen retrieval method was performed, as previously described. ${ }^{21}$ The tissue was then permeabilized in 0.15 $\mathrm{mol} / \mathrm{L}$ PB using $0.4 \%$ Triton-X100, blocked with $10 \%$ goat serum in PB with $0.4 \%$ Triton-X100 and incubated with the primary antibody in $0.15 \mathrm{Mol}$ PB with $0.4 \%$ Triton$X 100$, and $1 \%$ normal goat serum. Sections were then rinsed in PB and incubated with Alexa Fluor 568 or 488 goat anti-mouse and goat anti-rat secondary antibody (1:2000). Tissue was subsequently washed with PB, allowed to dry overnight, and the slides were then sealed with coverslips. Additional sections were incubated with Olig2, CC-1 (1:500, EMD chemicals, Inc., San Diego, $\mathrm{CA}$ ), or neurofilament-specific (NF) antibody, $2 \mathrm{H} 3$, (1: 500, Developmental Studies Hybridoma Bank, IL) using the same method above with a few modifications. The sections were permeabilized in $0.1 \%$ TX-100 instead of $0.4 \% \mathrm{TX}-100,0.1 \mathrm{~mol} / \mathrm{L}$ PBS was used instead of PB, and the antigen retrieval step was not performed. Stained sections were visualized using an Olympus BX50WI (Olympus, Melville, NY) and Leica SP1 (Leica Microsystems Inc, Bannockburn, IL) microscopes, and images were captured under $\times 40$ magnification. Three consecutive sections from both hemispheres for each mouse (4-6 mice total per genotype per age) for the different regions of the hippocampus were analyzed using ImageJ software version 1.38x (National Institutes of Health, Bethesda, MD). The pixel intensities for CNPase, MBP, and $\mathrm{NF} 2 \mathrm{H} 3$ for the images were analyzed and averaged across all images and mice within a group. Total CC-1 and Olig2positive cell counts were also performed using ImageJ software and the final counts averaged across all images and mice within a group. The investigator was blinded to the identity of each experimental group.

\section{Immunohistochemical Detection and Analysis of APP, $A \beta_{1-42}$, Human Tau, Phosphorylated Human Tau, and IBs}

Immunohistochemical analysis for $A \beta_{1-42}$, and tau was performed on Non-Tg and $3 \times \mathrm{Tg}-\mathrm{AD}$ mouse brain tissue, as previously described. ${ }^{11}$ Briefly, brain sections were washed in $0.15 \mathrm{~mol} / \mathrm{L} \mathrm{PB}$ and then placed in $3 \% \mathrm{H}_{2} \mathrm{O}_{2}$ to quench endogenous peroxidase activity. For $\mathrm{A} \beta_{1-42}$ staining the sections were mounted on the slide, allowed to dry, treated with Dako target retrieval buffer (Dako, Carpinteria, $\mathrm{CA}$ ), washed in $\mathrm{PB}$, permeabilized in $\mathrm{PB}$ with $0.4 \%$ Triton X-100 in PB. This step was followed by blocking in PB with $0.4 \%$ Triton X-100 plus $10 \%$ normal goat serum. For all other stainings, sections were washed in PB, permeabilized, and then placed in blocking solution. Next, the sections were incubated in primary antibodies, 
Y188 (1:1000, Abcam, Cambridge, MA); anti-A $\beta_{1-42} 12 \mathrm{~F} 4$ (1:1000, Covance, Berkeley, CA) for extracellular $A \beta_{1-42}$; anti-A $\beta_{1-42}$ polyclonal antibody (1:1000, Invitrogen) for intracellular $A \beta_{1-42} ; H T 7$ antibody (1:200, Pierce, Rockford, IL), AT180 antibody (1:200, Pierce), and c-myc, clone $9 \mathrm{E} 10(1: 1000$, Sigma) in $0.15 \mathrm{~mol} / \mathrm{L} \mathrm{PB}$ with $0.4 \%$ Triton $\mathrm{X}-100$, and $1 \%$ normal goat serum. The tissue was washed again and placed in appropriate biotin-conjugated secondary antibodies (1:1000, Vector Laboratories, Burlingame, $C A$ ) in $0.15 \mathrm{~mol} / \mathrm{L}$ PB with $0.4 \%$ Triton $X-100$, and $1 \%$ normal goat serum. Sections were washed in PB and then incubated in avidin-biotin complex per the manufacturer's protocol (Vectastain ABC System, Vector Laboratories) and developed using nickelenhanced DAB. Floating sections were mounted on glass slides, allowed to air dry, sealed using mounting medium (Richard-Allan Scientific, Hudson, NH), and coverslipped. The stain was visualized and images were captured using an Olympus DP71 microscope or Olympus VanoxAH-2.

\section{Electron Microscopy}

Mice were perfused transcardially, the brain was removed, coronally sectioned to $1 \mu \mathrm{m}$ to include the hippocampal formation at $1.70 \mathrm{~mm}$ to $3.40 \mathrm{~mm}$ posterior to Bregma, and placed in fresh fixative (4.0\% paraformaldehyde $/ 2.0 \%$ glutaraldehyde in $0.1 \mathrm{~mol} / \mathrm{L}$ sodium cacodylate buffer). The sections were further trimmed to include the Schaffer collaterals, postfixed in $1.0 \%$ osmium tetroxide, dehydrated, and embedded in Epon. Ultra-thin sections were counterstained with uranyl acetate fol- lowed by lead citrate and examined using a Hitachi 7100 transmission electron microscope. Images for myelin sheath integrity of the Schaffer collateral axons were captured using a MegaView III digital camera and AnalySIS (Soft Imaging Systems, Lakewood, Colorado) software. Images were captured at $\times 10,000$ magnification.

\section{Statistical Analysis}

Statistical analysis was performed by means of Student's $t$-test or 2-way analysis of variance followed by the Bonferroni posttest using GraphPad Prism version 5.0 for Mac OS (GraphPad Software, San Diego, CA).

\section{Results}

\section{Myelin Disruption in the Brains of $3 \times T g-A D$ Mice}

Myelin and oligodendrocyte alterations have been previously described in the hippocampal subregions of $3 x$ Tg-AD mice. ${ }^{5}$ Previously, significant alterations in oligodendrocyte and myelin markers CNPase and MBP and ultrastructural changes in myelin sheath integrity of $3 \times \mathrm{Tg}-\mathrm{AD}$ mice were demonstrated. Herein, we further examined myelin status in the CA1 region of the hippocampus in the brains of $3 \times \mathrm{Tg}-\mathrm{AD}$ and Non-Tg mice at 6 months of age and sought to determine the pathogenic source of these alterations. Qualitative assessment of Black-Gold II myelin staining revealed a decline in staining intensity in the CA1 region of the hippocampus of $3 \times$ Tg-AD mice (Figure 1, A and B). Quantitative analysis
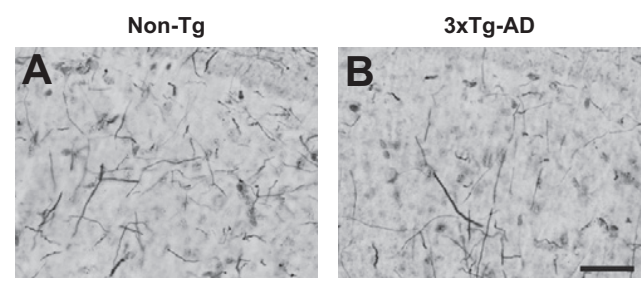

C

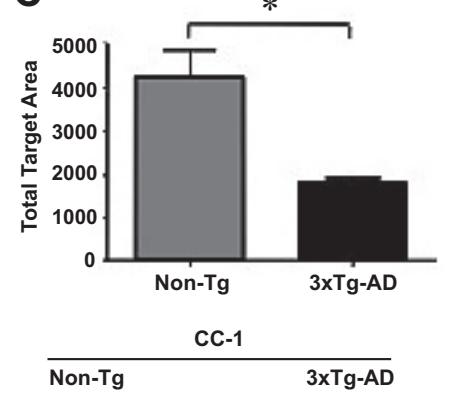

Figure 1. Alterations in myelin and oligodendrocyte cell number are observed in the brain regions of $3 \times \mathrm{Tg}-\mathrm{AD}$ mice. Black-Gold II stain for myelin was performed on 6-month-old $3 \times \mathrm{Tg}$-AD and Non-Tg mice. Representative coronal images of the myelin staining patterns specifically in the CA1 hippocampal region (A and $\mathbf{B}$ ) of $3 \times \mathrm{Tg}-\mathrm{AD}$ mice compared with Non-Tg mice are illustrated. Quantitative analyses of myelin staining intensities and numbers of myelinated axons were performed (C and $\mathbf{D}$, respectively). Scale bars $=5 \mu \mathrm{m} . N=3$ per genotype. Coronal sections of 6-month-old Non-Tg (E and $\mathbf{G}$ ) and $3 \times \mathrm{Tg}-\mathrm{AD}$ mice $(\mathbf{F}$ and $\mathbf{H})$ were immunostained for the CC-1 and Olig2 oligodendrocyte markers. Representative images for CC-1 (E and F) and Olig2 (G and $\mathbf{H}$ ) staining for Non-Tg and $3 \times \mathrm{Tg}-\mathrm{AD}$ mice are depicted. Quantitative analyses were subsequently performed to determine the numbers of CC-1- (I) or Olig2positive cells $(\mathbf{J})$. Scale bars $=5 \mu \mathrm{m} . N=6$ per genotype ${ }^{*} P<0.05$.
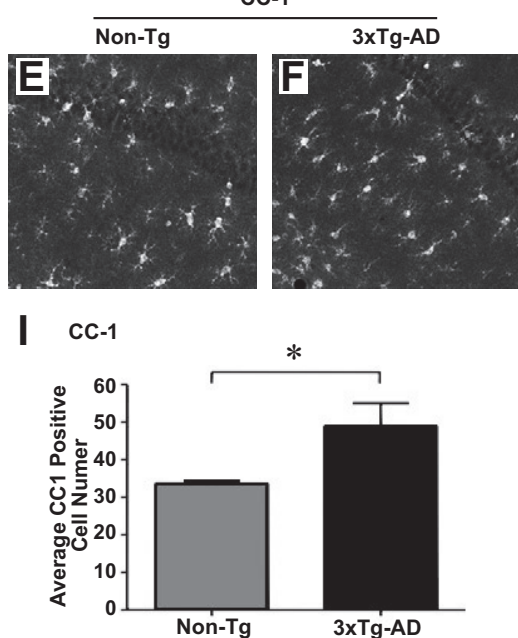

D
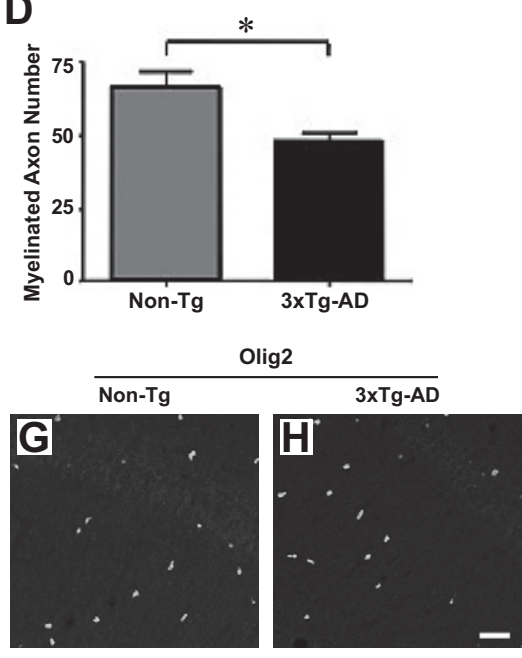

J Olig2

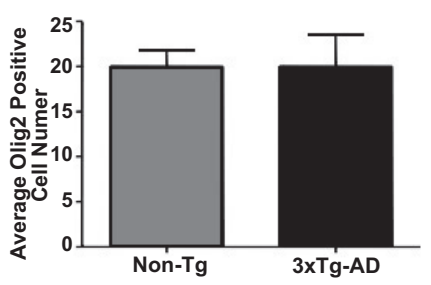


of the pixel intensity of myelin staining in the $C A 1$ region indicated a significant decrease in 6-month-old $3 \times \mathrm{Tg}-\mathrm{AD}$ mice compared with age-matched Non-Tg counterparts (Figure 1C). Additionally, we stereologically quantified myelinated fibers in the CA1, which demonstrated a decline in the total number of myelinated processes in 6 month-old $3 \times \mathrm{Tg}-\mathrm{AD}$ mice (Figure 1D).

The relative numbers of mature and immature oligodendrocytes in the CA1 region of the hippocampus were subsequently assessed using adenomatous polyposis coli (APC; also CC-1), a mature oligodendrocyte marker that stains cell bodies and Olig2 marker for immature oligodendrocytes. We had previously shown that $3 \times \mathrm{Tg}-\mathrm{AD}$ mice exhibit decreased numbers of MBP-positive myelinating oligodendrocytes within the hippocampus and entorhinal cortex by 6 months of age. ${ }^{5}$ The staining patterns for CC-1 (Figure 1, E and F) and Olig2 (Figure 1, G and H) are depicted in representative images for Non-Tg and $3 \times$ Tg-AD mice. Quantitative analyses revealed a statistically significant elevation in the total number of CC-1-positive cells (Figure 11), whereas numbers of Olig2-positive immature oligodendrocytes remained unchanged (Figure 1J).

\section{AD-Related Pathology in the Brains of $3 \times T g-A D$ Mice}

The age at which these alterations in oligodendrocyte marker expression and myelin staining patterns arise are at a time when $3 \times \mathrm{Tg}-\mathrm{AD}$ mice do not exhibit overt AD-related pathology. ${ }^{20}$ To confirm the AD pathology status at the ages examined in the current study, immunohistochemistry was performed on the brains of $3 \times \mathrm{Tg}-\mathrm{AD}$ and Non-Tg mice for amyloid precursor protein (APP), intracellular and extracellular $A \beta_{1-42}$, human tau, and phosphorylated human tau protein. Qualitative analysis of marker expression revealed no alterations in the expression of human APP in the CA1 region of the brains of 2- and 6-month-old $3 \times \mathrm{Tg}-\mathrm{AD}$ mice (Figure 2, $A$ and $B$ ). Intracellular $A \beta_{1-42}$ levels are qualitatively enhanced in 6-month-old 3×Tg-AD mice (Figure 2, C and $D$ ) whereas extracellular $A \beta_{1-42}$ deposits remain undetectable at both 2 and 6 months of age (Figure 2, E and F). Western blot and dot blot analyses were performed to further assess the levels of $A \beta$ peptide species in the brains of $3 \times \mathrm{Tg}-\mathrm{AD}$ and Non-Tg (C57BL/6) mice at 2 and 6 months of age. The $3 \times T$ Tg-AD mice exhibited enhanced levels of $A \beta_{1-42}$ conformers between 2 and 6 months of age (Figure $2 \mathrm{G}$ ). Furthermore, quantification of dots blot analysis using an oligomer-specific antibody (I11; kindly provided by Dr. C. Glabe) revealed significantly higher levels of $A \beta$ oligomers in 3XTg-AD mice compared with Non-Tg mice $(P<0.05)$ (Figure $2 \mathrm{H})$. Dot blot analyses also confirmed an age-related increase in $A \beta$ oligomers in 6-month-old 3XTg-AD mice compared with 2-month-old mice. Tau immunohistochemistry indicated human tau transgene staining was qualitatively stable at both time points (Figure 2, I and J), while AT180-detected phospho-tau was readily apparent in the CA1 hippocampal region of 6 month-old $3 \times$ Tg-AD mice, but not at 2 months of age (Figure $2, K$ and $L$ ).

\section{Cell Death of mOP Cells Is Induced by $A \beta_{1-42}$}

The myelin abnormalities and subtle myelin loss found in human AD brain and mouse models of the disease could arise as a result of a disease-related "signal" that directly or indirectly impacts the function and/or viability of oligodendrocytes. The slight, but detectable, accumulation of $A \beta_{1-42}$ in the brains of young $3 \times \mathrm{Tg}-A D$ mice suggests that these pathogenic peptide species may exact untoward effects on the oligodendrocyte lineage during early pathogenesis. To initially examine the susceptibility of oligodendrocytes to $A \beta$ peptide exposure, we used a mOP cell line developed in the laboratory of Dr. Steven Reeves. ${ }^{16}$ These cells exhibit morphological and marker expression profiles reminiscent of nondifferentiated or differentiated oligodendrocytes depending on predetermined culture conditions. For the current study, mOP cells were cultured to assess whether differentiation status influenced sensitivity to fibrillogenic $A \beta_{1-42}$ peptide. Nondifferentiated mOP cells assume bipolar/tripolar morphology and elongated cell body and on differentiation depict multipolar morphology and rounded cell body (Figure 3, A-D). We further confirmed the staging of mOP cells by examining the expression of oligodendrocyte cell markers $2^{\prime}, 3^{\prime}$-cyclic nucleotide $3^{\prime}$-phosphodiesterase (CNPase), which is expressed by cells throughout the lineage, and MBP, which is expressed by mature myelinating oligodendrocytes. ${ }^{22}$ As expected, nondifferentiated mOP cells express CNPase but lack MBP expression (Figure 3, E and F), while differentiated $\mathrm{mOP}$ cells express both CNPase and MBP (Figure $3, \mathrm{G}$ and $\mathrm{H}$ ). After confirming differentiation status evoked under each culture condition, $\mathrm{mOP}$ cells were incubated with human $A \beta_{1-42}$ or reverse $A \beta_{42-1}$ control peptide for 4 hours, and cell death was assessed using Hoechst staining, which facilitates detection of fragmented or condensed nuclei, signs reminiscent of apoptotic cell death. Analyses of Hoechst-stained mOP cells revealed a significant increase in the number of cells with pyknotic nuclei following $A \beta_{1-42}$ peptide treatment in both nondifferentiated and differentiated mOP cells (Figure $3, I$ and J, respectively), as compared with companion cultures treated with the control $\mathrm{A} \beta_{42-1}$ reverse peptide.

Active caspase-3 has been used extensively as a marker for apoptosis. ${ }^{22}$ Possibly more relevant, prior studies have demonstrated increased caspase-3 expression in neurons, astrocytes, and blood vessels in AD brains and implicated this protease in the functional decline of neurons in $A D .23,24$ To this end, immunohistochemical analyses for active caspase- 3 was performed on $A \beta$ peptide-treated nondifferentiated (Figure 3, K and M) and differentiated (Figure 3, L and $\mathrm{N}$ ) $\mathrm{mOP}$ cells, and the percentage of active caspase3-positive cells was determined. mOP cultures exposed to $\mathrm{A} \beta_{1-42}$ peptide exhibited a significant increase in the percentage of cells expressing active caspase-3, regardless of differentiation state, as compared with cultures treated with the reverse peptide control. Collectively, these data indicate cultured oligodendrocytes exhibit a differentiation state-independent sensitivity to $A \beta_{1-42}$ toxicity and suggest that this $A D$-related pathogenic peptide may be a key role in directly affecting oligodendrocyte viability and myelin status in vivo. 

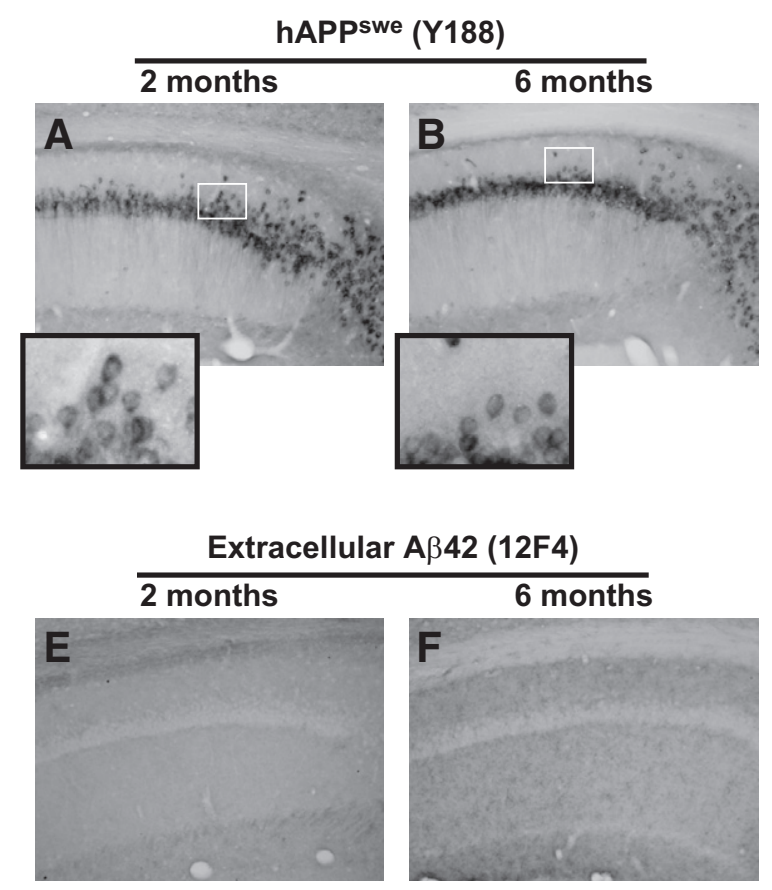

Human tau (HT7)
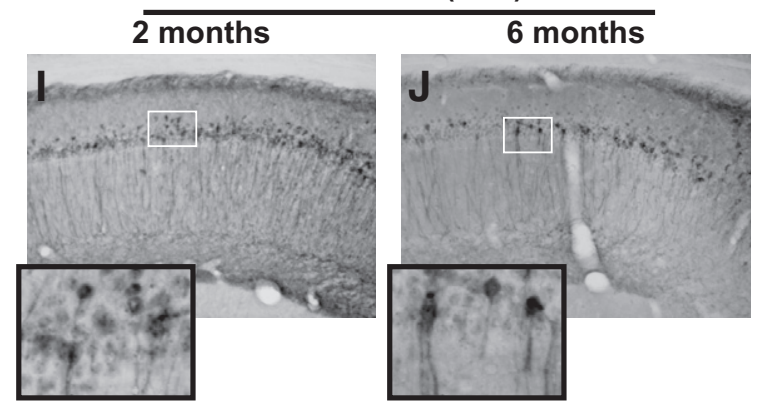
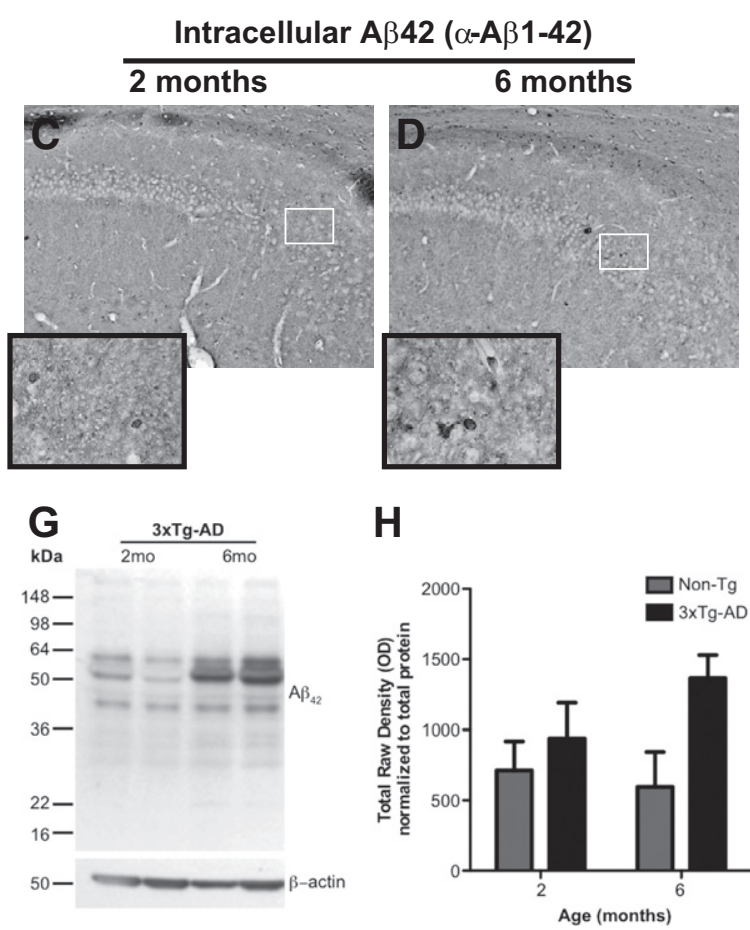

Phospho-tau (AT180)
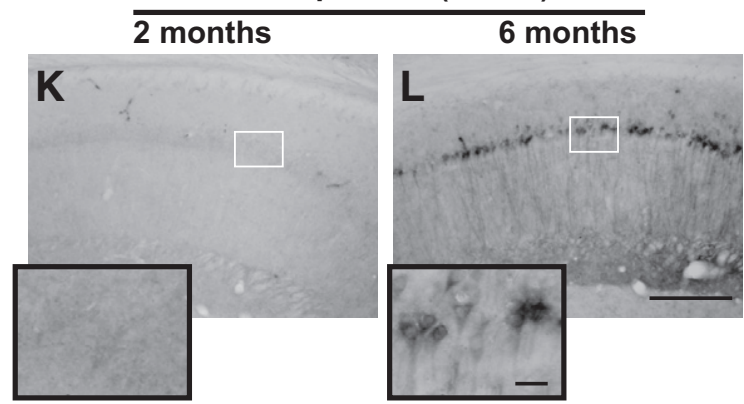

Figure 2. AD-related pathology in the brains of $3 \times \mathrm{Tg}-\mathrm{AD}$ mice at two and six months of age. Immunohistochemistry was performed on nonmanipulated 2- and 6-month-old $3 \times \mathrm{Tg}$-AD to assess human amyloid precursor protein (hAPP), intracellular and extracellular A $\beta_{1-42}$, tau, and phosphorylated tau expression. Representative images for APP, intracellular $\mathrm{A} \beta_{1-42}$, and extracellular $\mathrm{A} \beta_{1-42}$ expression $(\mathbf{A}-\mathbf{F})$ in the $\mathrm{CA} 1$ region of the hippocampus of $3 \times \mathrm{Tg}-\mathrm{AD}$ mice are demonstrated. Insets represent $\times 100$ magnification images of protein expression in the neurons of the CA1 hippocampal region. Western blot and dot blot analyses were performed on microdissected entorhinal cortex brain tissue of 2 - and 6-month-old Non-Tg and 3XTg-AD mice to assess oligomeric forms of A 3 . Representative western blots showing oligomeric A $\beta$ levels $(\mathbf{G})$ in the entrohinal cortex region of $3 \times \mathrm{Tg}-\mathrm{AD}$ mice, and quantitation of dots blots $(\mathbf{H})$ for Non-Tg and $3 \times \mathrm{Tg}-\mathrm{AD}$ mice are shown. Representative images of human tau and phosphorylated human tau protein are also illustrated (I-L) for the CA1 region of the brain for $3 \times \mathrm{Tg}-\mathrm{AD}$ mice at two and six months of age. Scale bars $=10 \mu \mathrm{m}$ for the images and $200 \mu \mathrm{m}$ for the insets. $N=6$ for immunohistochemistry, and $N=2$ for Western and dot blots.

\section{Engineering and in Vivo Delivery of rAAV Vectors}

We next used a previously engineered IB targeted specifically against $A \beta_{1-42}$ and stereotactically delivered the IB in vivo via a viral vector to assess the effects of $A \beta$ perturbation on oligodendrocyte and myelination status in $3 \times \mathrm{Tg}-\mathrm{AD}$ mouse brain. ${ }^{18}$ The constructed PAAV vectors expressed a phenobarbitol or $\mathrm{A} \beta_{1-42^{-}}$ specific IB sequence harboring an in-frame ER targeting signal (KDEL) and a c-myc epitope tag at the $\mathrm{C}$ terminus under the transcriptional control of the cytomegalovirus promoter (Figure 4A). ${ }^{18}$ We previously demonstrated that these IBs are preferentially targeted to the ER of cells in vitro and in vivo. ${ }^{18}$ Baby hamster kidney cells were subsequently transiently transfected with the pAAV vector plasmids, and DAB immunohis- tochemistry was performed to verify IB expression (Figure 4, B-D). Subsequently, the plasmid vectors were packaged into serotype-2 virions to restrict IB expression to neurons ${ }^{25}$ and sterotactically infused into the hippocampi of 2-month-old $3 \times \mathrm{Tg}-\mathrm{AD}$ and Non-Tg mice using bilateral convection enhanced delivery (CED) to facilitate distribution of IB-expressing AAV particles. Mice were sacrificed and brains were analyzed 4 months post-transduction (6 months of age). ${ }^{26,27} \mathrm{Im}$ munohistochemistry for c-myc was performed, and the results revealed comparable $\mathrm{rAAV}$-scFvphe ${ }_{\mathrm{KDEL}}{ }^{\mathrm{IB}}$ and rAAV-scFVA $\beta_{\mathrm{KDEL}}{ }^{\mathrm{IB}} \mathrm{IB}$ staining in the transduced CA1 hippocampal field (Figure 4E-L). Co-immunohistochemistry for IB and the neuronal marker NeuN demonstrated that IB expression was restricted to pyramidal neurons of the vector-infused CA1 subregion (Figure 4, M-X). 
Non-differentiated

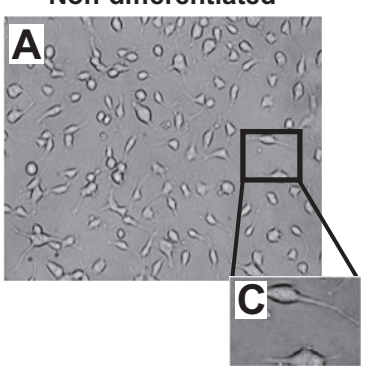

Differentiated

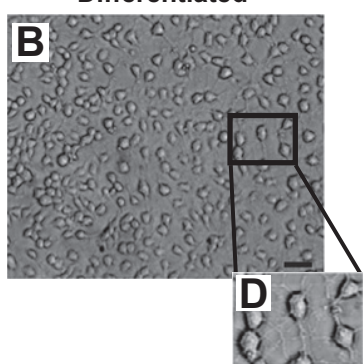

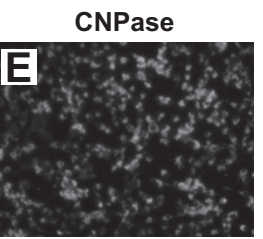
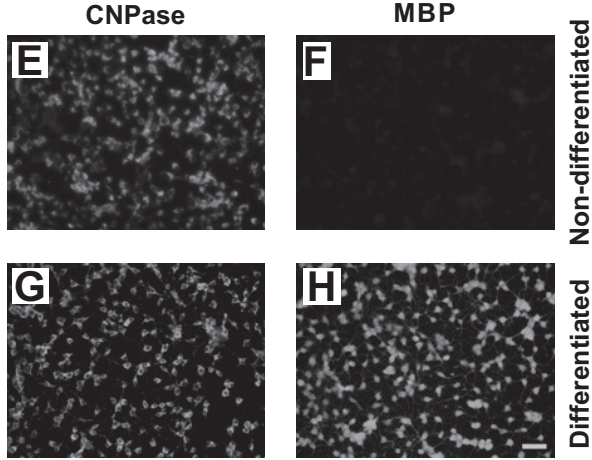

| Non-differentiated
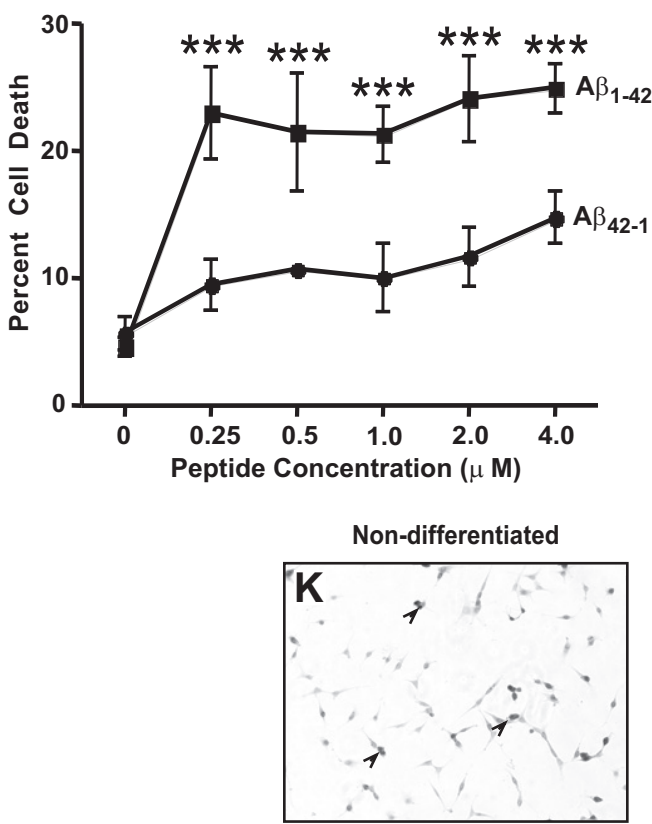

M Non-differentiated

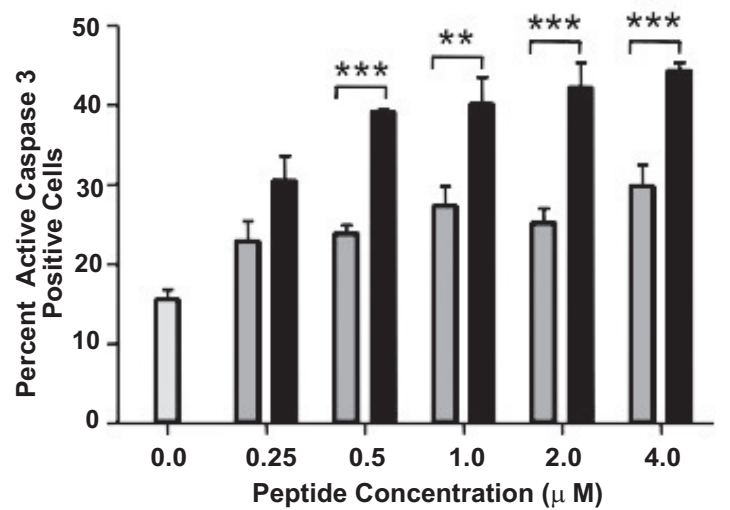

J Differentiated
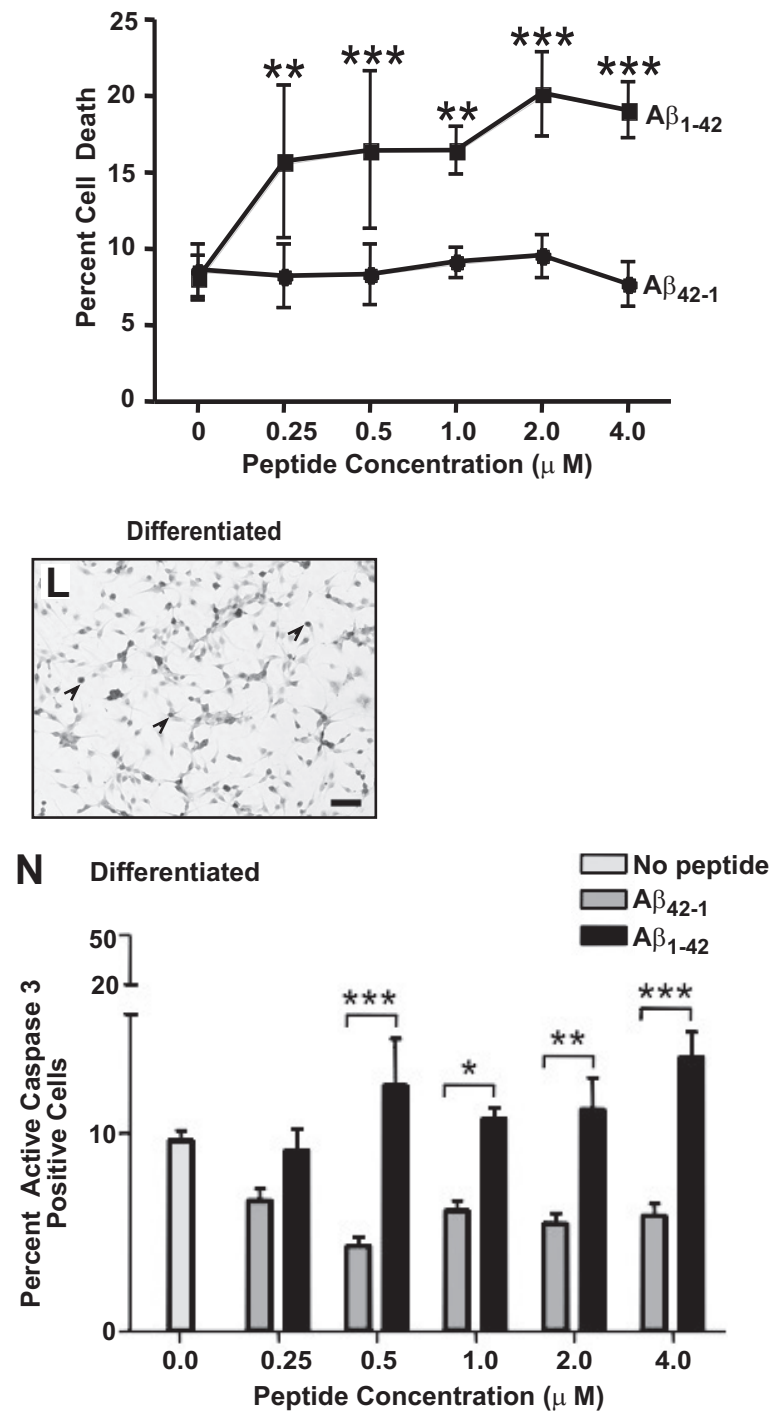

Figure 3. $\mathrm{A} \beta_{1-42}$ induced toxicity and enhancement of active caspase 3 in nondifferentiated and differentiated mOP cells. Phase contrast photomicrographs of nondifferentiated (A) and differentiated cells (B) are depicted. The insets are digitally magnified to $60 \%$ the original image to illustrate bipolar morphology of nondifferentiated cells $(\mathbf{C})$ and multiprocess mature morphology on differentiated cells (D). Nondifferentiated and differentiated cells were stained using CNPase ( $\mathbf{E}$ and $\mathbf{G}$, respectively) and MBP (F and $\mathbf{H}$, respectively) to determine the maturation stages of the cells. mOP cultures were subsequently treated with $0-4 \mu \mathrm{mol} / \mathrm{L} \mathrm{A} \beta_{1-42}$ and $\mathrm{A} \beta_{42-1}$ peptides for four hours. mOP cell death was determined using Hoecsht 33342 staining for both nondifferentiated (I) and differentiated cells $(\mathbf{J})$. Immunocytochemistry for active caspase 3 was performed on fixed mOP cells, and representative image for nondifferentiated and differentiated cells are depicted (K and $\mathbf{L}$, respectively). Arrowheads point to active caspase-3-positive cells. Quantification of active caspase- 3 positive mOP cells was performed for both nondifferentiated (M) and differentiated (N) cultures. An average of $1000-5605$ cells were enumerated per condition $(N=4)$ per experiment. A total of three and two independent experiments were performed, respectively. Scale bars $=5 \mu \mathrm{m}$. Error bars indicate SD. ${ }^{*} P<0.05$; ${ }^{* * * *} P<0.001$. 
A
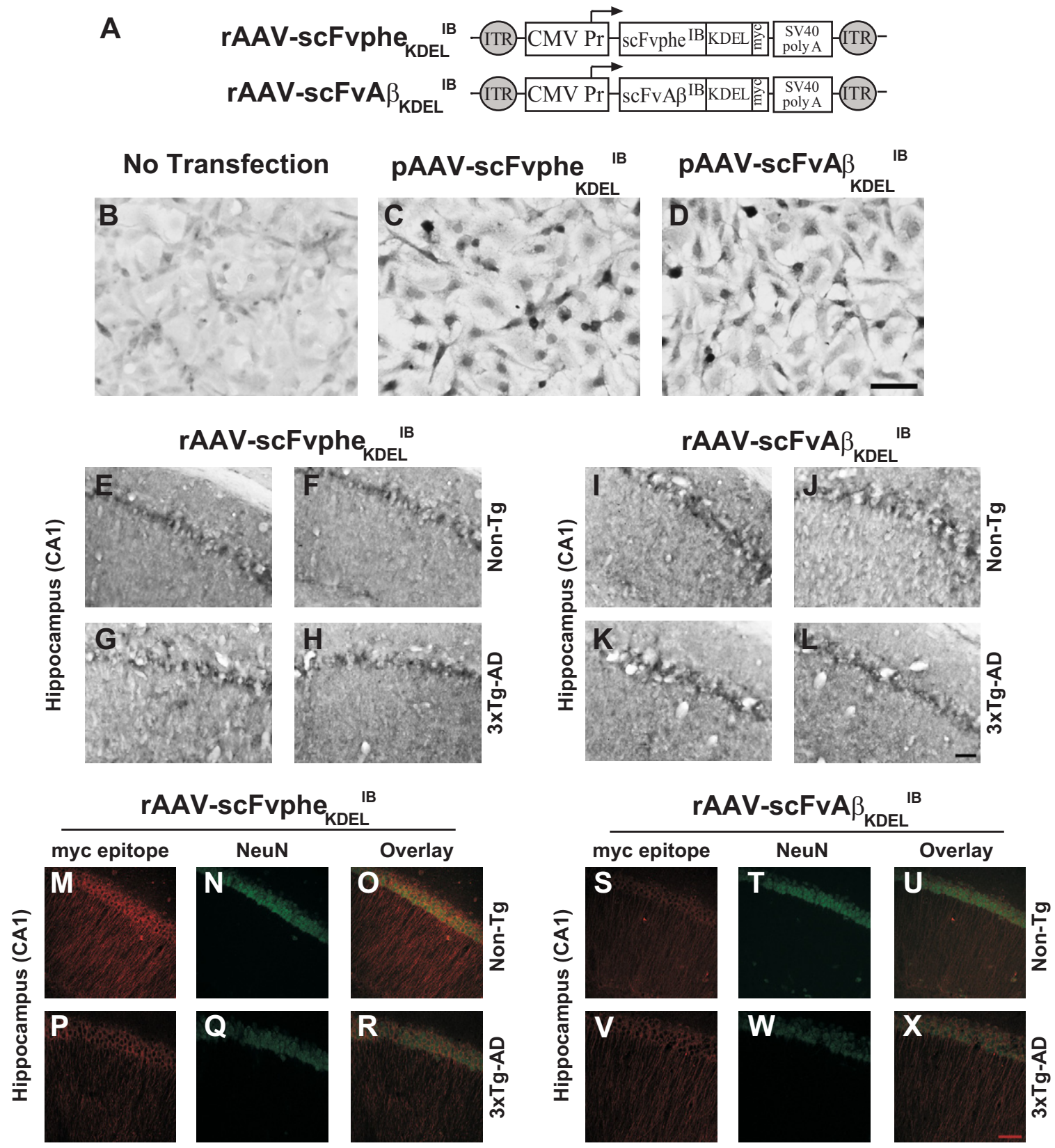

Figure 4. Construction and in vivo assessment of IB-expressing rAAV2 vectors. Schematic representations of the recombinant adeno-associated virus plasmid constructs, pAAV-scFvphe ${ }_{\mathrm{KDEL}}{ }_{\mathrm{IB}}$ and pAAV-scFvA $\beta_{\mathrm{KDEL}}{ }^{\mathrm{IB}}$, are shown $(\mathbf{A})$. The vectors harbor the human cytomegalovirus promoter driving a c-myc epitope-tagged and KDEL endoplasmic reticulum targeting signal-tagged scFv IB specific for either phenobarbital (scFvphe ${ }_{\mathrm{KDEL}}{ }^{\mathrm{IB}}$ ) or $\mathrm{A} \beta_{1-42}$ (scFvA $\beta_{\mathrm{KDEL}}{ }^{\mathrm{IB}}$ ), followed by a SV40 poly A signal. ${ }^{18}$ The entire transcription unit is flanked by AAV-derived inverted terminal repeats. Baby hamster kidney cells were transiently transfected with the pAAV vectors, and DAB immunohistochemistry was performed for c-myc epitope (B-D). These rAAV vectors were packaged into serotype-2 capsids using a previously described baculovirusbased method ${ }^{18}$ and stereotactically injected into the hippocampus of 2-month-old Non-Tg and $3 \times \mathrm{Tg}$-AD mice. The mice were sacrificed at 6 months of age, the brains were harvested, and DAB immunohistochemistry was performed for c- $m y c$ to detect rAAV-scFvphe ${ }_{\mathrm{KDEL}}{ }^{\mathrm{IB}}$ and rAAV-scFvA $\beta_{\mathrm{KDEL}}{ }^{\mathrm{IB}}$ expressed IB in the vector infused CA1 subregion of the hippocampus (E-L). Co-immunohistochemistry was further performed using c-myc (red; $\mathbf{M}, \mathbf{P}, \mathbf{S}, \mathbf{V}$ ) and NeuN (green; $\mathbf{N}, \mathbf{Q}, \mathbf{T}, \mathbf{W}$ ) to assess cell type specificity of IB expression. Colocalized fluorescence is depicted in the overlay panels (yellow; $\mathbf{O}, \mathbf{R}, \mathbf{U}, \mathbf{X}$ ). Scale bars $=5 \mu \mathrm{m} . N=6$ per genotype per vector condition.

Myelin and Oligodendrocyte Marker Status Is Restored in 3×Tg-AD Mice Transduced with rAAV-SCFVA $\beta_{K D E L}{ }^{I B}$

To determine whether IB-mediated abrogation of $A \beta_{1-42}$ release from neurons would rescue the white matter pathology observed in $3 \times \mathrm{Tg}-\mathrm{AD}$ mice, oligodendrocyte/ myelin marker staining profiles were assessed in the brains of rAAV vector-infused $3 \times \mathrm{Tg}-\mathrm{AD}$ and Non-Tg mice. Analyses of CNPase and MBP markers were performed in the transduced CA1 hippocampal region. Examination of CNPase staining revealed no significant changes between the various treatment groups (Figure 5, A-D and $\mathrm{M})$. While MBP expression levels remained unchanged in CA1 region of the Non-Tg mice injected with $\mathrm{rAAV}$ scFvphe $_{\mathrm{KDEL}}{ }^{\mathrm{IB}}$ and $\mathrm{rAAV}-\mathrm{scFVA} \beta_{\mathrm{KDEL}}{ }^{\mathrm{IB}}$, MBP staining intensities were restored in $3 \times \mathrm{Tg}-\mathrm{AD}$ mice intrahippocampally infused with $\mathrm{rAAV}_{\mathrm{SCF}} \mathrm{AA} \beta_{\mathrm{KDEL}}{ }^{\mathrm{IB}}$ (Figure 5, E-H and 

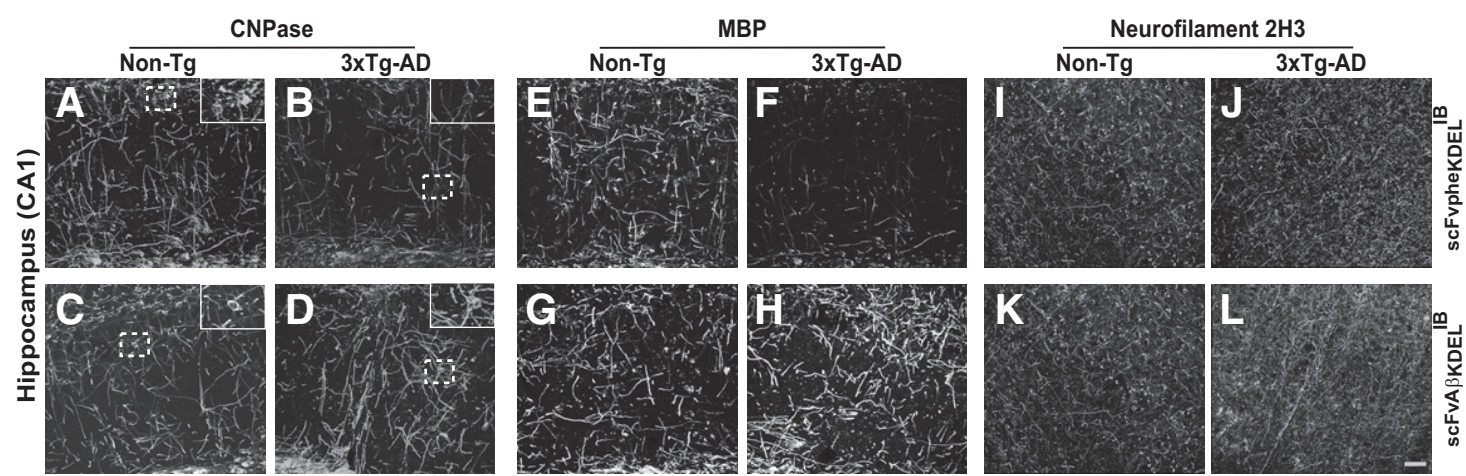

M cNPase

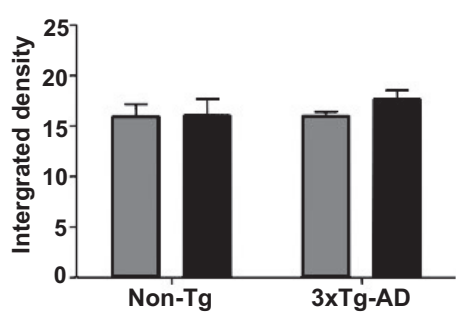

$\mathbf{N}_{\text {MBP }}$

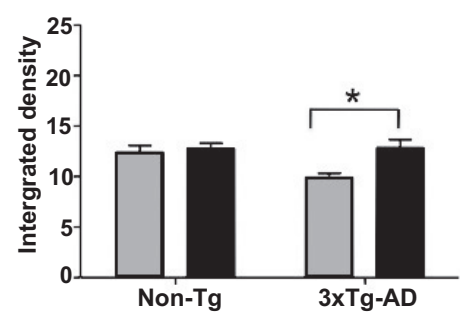

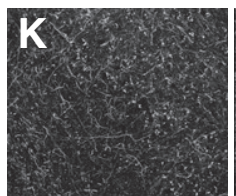
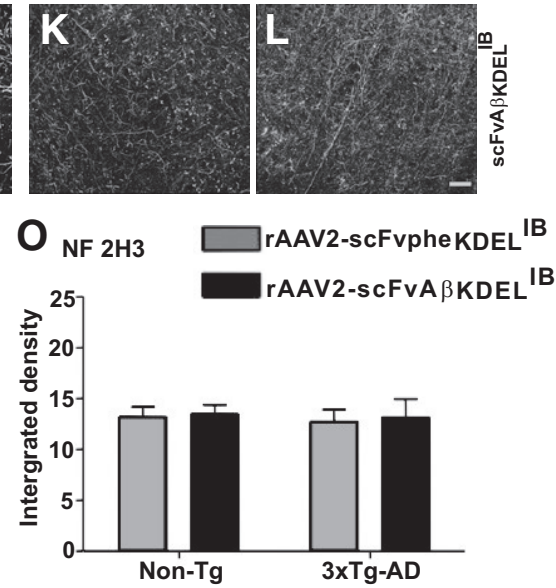

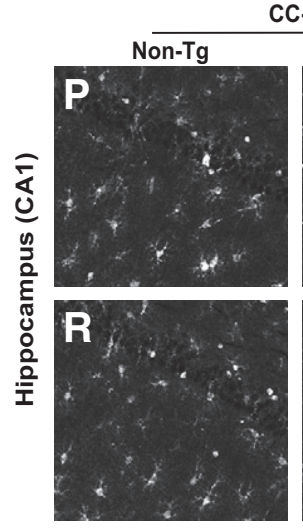

$3 \times \operatorname{Tg}-\mathrm{AD}$
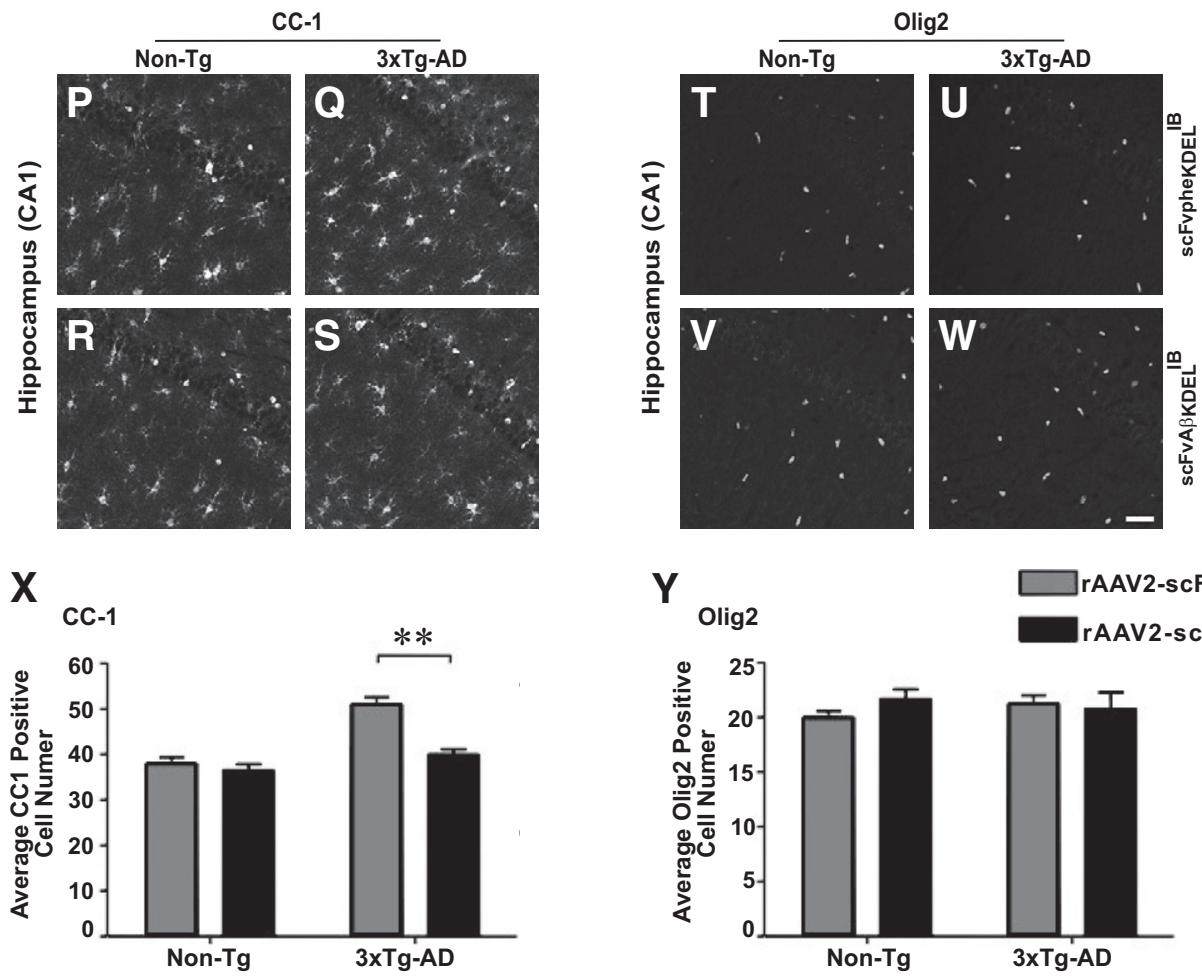

Y

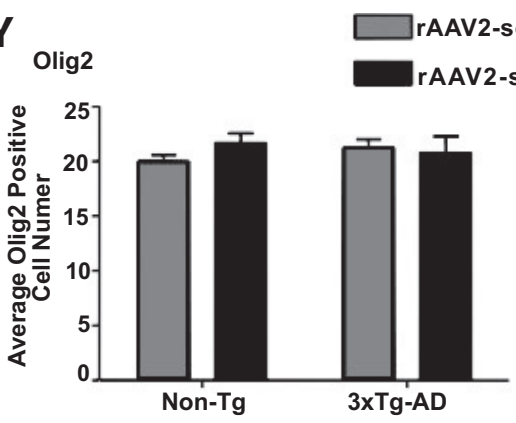

Figure 5. Restoration of oligodendrocyte/myelin status and oligodendrocyte numbers in CA1 region of the hippocampus in the brains of rAAV-scFVA $\beta_{\mathrm{KDEL}}{ }^{\mathrm{IB}}$ injected $3 \times$ Tg-AD mice. Coronal sections from 6-month-old rAAV-scFvphe ${ }_{\mathrm{KDEL}}{ }^{\mathrm{IB}}(\mathbf{A}, \mathbf{B}, \mathbf{E}, \mathbf{F}, \mathbf{I}, \mathbf{J})$ or rAAV-scFvA $\beta_{\mathrm{KDEL}}{ }_{\mathrm{IB}}(\mathbf{C}, \mathbf{D}, \mathbf{G}, \mathbf{H}, \mathbf{K}, \mathbf{L})$ injected Non-Tg $(\mathbf{A}, \mathbf{C}, \mathbf{E}, \mathbf{G}, \mathbf{I}, \mathbf{K})$ and $3 \times \mathrm{Tg}-\mathrm{AD}$ mice $(\mathbf{B}, \mathbf{D}, \mathbf{F}, \mathbf{H}, \mathbf{J}, \mathbf{L})$ were stained with antibodies specific for CNPase $(\mathbf{A}-\mathbf{D}), \mathrm{MBP}(\mathbf{E}-\mathbf{H})$, or neurofilament $(\mathbf{I}-\mathbf{L})$, and representative microscopic images are depicted $(\mathbf{A}-\mathbf{L})$. Insets represent $\times 2$ magnification of the original selection and depict CNPase-positive cell body staining patterns in the hippocampus $(\mathbf{A}-\mathbf{D})$. Quantitation of CNPase $(\mathbf{M}), \operatorname{MBP}(\mathbf{N})$, and NF $(\mathbf{O})$ immunopositivity was performed by calculating integrated densities across each genotype and treatment group. Scale bars $=5 \mu \mathrm{m}$. Coronal sections from 6-month-old rAAV-scFvA $\beta_{\mathrm{KDEL}}{ }_{\mathrm{IB}}$ or rAAV-scFvphe ${ }_{\mathrm{KDFI}}{ }^{\mathrm{IB}}$ injected Non-Tg and $3 \times \mathrm{Tg}-\mathrm{AD}$ mice were also immunostained for the CC- 1 and Olig2 oligodendrocyte markers. Representative images for CC-1 (P-S) and Olig2 (T-W) for the CA1 hippocampal region are depicted for the 6-month-old rAAV2 vector-injected Non-Tg $(\mathbf{P}, \mathbf{R}, \mathbf{T}, \mathbf{V})$ and $3 \times \mathrm{Tg}$-AD mice $(\mathbf{Q}, \mathbf{S}, \mathbf{U}, \mathbf{W})$. Quantitative analyses were also performed to assess the numbers of CC-1 $(\mathbf{X})$ and Olig2 positive cells $(\mathbf{Y})$ in the CA1 region of the hippocampus. Scale bars $=5 \mu \mathrm{m}$. Error bars indicate SD $N=6$ per genotype per treatment. ${ }^{*} P<0.05$; ${ }^{* *} P<0.01$.

N). As expected, MBP staining was markedly lower in $3 \times$ Tg-AD mice injected with the rAAV-scFvphe ${ }_{\mathrm{KDEL}}{ }^{\mathrm{IB}}$ control vector, which is similar to what was previously reported in non-manipulated 6 month-old $3 \times$ Tg-AD mice. ${ }^{5}$
To confirm that the axonal integrity in the brains of the $3 \times$ Tg-AD and Non-Tg mice was maintained after the invasive stereotactic injection and to verify that axonal integrity was not a contributing factor toward the differ- 

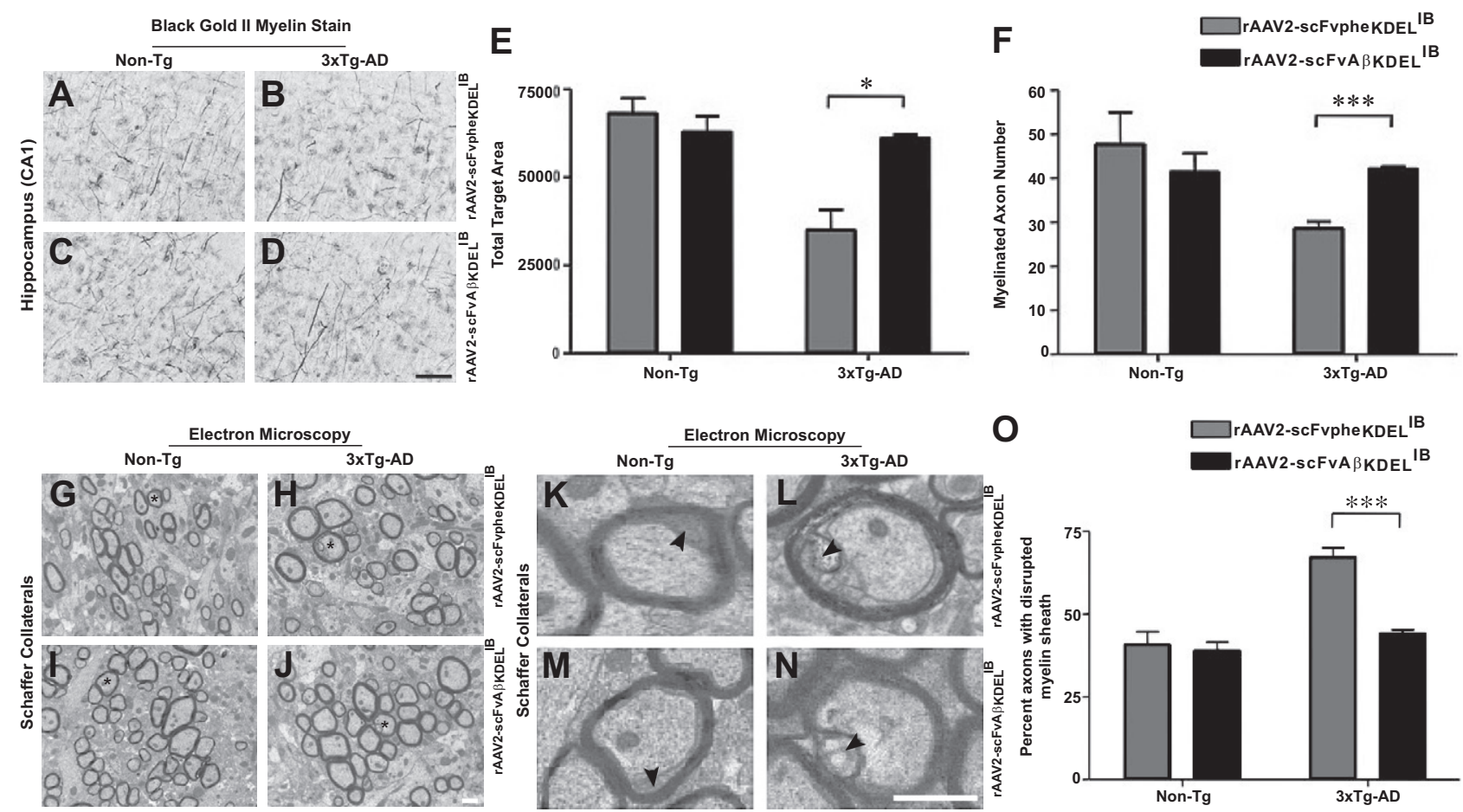

Figure 6. Myelin disruptions are significantly dampened in $\mathrm{rAAV}$-scFvA $\beta_{\mathrm{KDFI}}{ }^{\mathrm{IB}}$-injected $3 \times \mathrm{Tg}-\mathrm{AD}$ mice. Black-Gold II stain for myelin was performed on coronal sections from rAAV2 vector-injected 6-month-old $3 \times \mathrm{Tg}-\mathrm{AD}$ and Non-Tg mice. Representative images of the myelin staining patterns in the CA1 hippocampal region $(\mathbf{A}-\mathbf{D})$ of rAAV2 vector-injected $3 \times \mathrm{Tg}-\mathrm{AD}$ mice compared with Non-Tg mice are illustrated. Quantitative analyses of myelin stain for pixel intensity and numbers of myelinated axons were performed for the rAAV2 vector-injected $3 \times \mathrm{Tg}$-AD mice and Non-Tg $(\mathbf{E}$ and $\mathbf{F}$, respectively). Scale bar $=5 \mu \mathrm{m}(\mathbf{D})$. $N=3$ per genotype. Electron microscopy was performed on the Schaffer collateral pathway fibers of coronal brain sections of 6-month-old rAAV2 vector-injected Non-Tg and $3 \times \mathrm{Tg}-\mathrm{AD}$ mice. Representative images from each treatment group are depicted $(\mathbf{G}-\mathbf{J})$. An asterisk $(*)$ represents axons with evidence of myelin sheath disruption. These marked axons were digitally magnified to $\times 4.5$ of original images to depict myelin sheath pathology in more detail (K-N). The arrowheads point to disrupted myelin sheaths with granular inclusions. Quantitative analyses determining axons with myelin sheath damage in both rAAV2

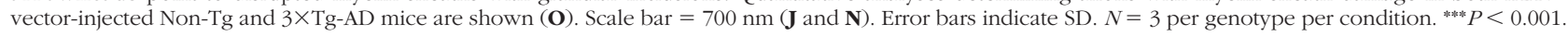

ences observed in the levels of the CNPase and MBP markers, immunohistochemistry for mouse NF $2 \mathrm{H} 3$ was performed. NF 2H3 staining patterns appeared unaltered in all groups of vector-infused mice (Figure 5, I-L). Quantitative analyses of $\mathrm{NF} 2 \mathrm{H} 3$ levels in the $\mathrm{CA} 1$ region further indicated comparable staining intensities of this neuronal marker across all groups of mice (Figure 50). Collectively, these results revealed that a strategy designed to impede extracellular $A \beta_{1-42}$ accumulation successfully restored expression of the myelinating oligodendrocyte marker, $\mathrm{MBP}$, in $3 \times \mathrm{Tg}-\mathrm{AD}$ mice to levels comparable to age-matched Non-Tg control mice without overtly impacting axonal integrity.

Immunocytochemical analysis of CC-1 (for mature oligodendrocytes) and Olig2 (for immature oligodendrocytes) marker expression in the brains of rAAV2 vectorinjected $3 \times \mathrm{Tg}-\mathrm{AD}$ and Non-Tg mice was additionally performed. Quantitation of CC-1-positive cells revealed that intrahippocampal infusion of $\mathrm{rAAV}-\mathrm{SCFVA} \beta_{\mathrm{KDEL}}{ }^{\mathrm{IB}}$ into $3 \times \mathrm{Tg}-\mathrm{AD}$ mice led to a reduction in CC-1-positive cell numbers that were comparable to Non-Tg control mice injected with either rAAV vector (Figure 5, P-S and X). The numbers of Olig2-positive immature oligodendrocytes remained unaltered in the brains of rAAV2 vectorinjected Non-Tg and 3×Tg-AD mice (Figure 5, T-W and $Y)$. These results suggest that the passive immune-based intervention altered the balance of MBP-positive (myelinating) versus CC-1-positive mature oligodendrocytes in favor of a more myelination-competent population. Shifting the ratio in such a manner could indicate rescue of the myelin defects that we have shown arise in unmanipulated 6-month-old 3×Tg-AD mice.

\section{Myelin Integrity Is Protected in $3 \times T$ Tg-AD Mice Transduced with $r A A V$-scFVA $\beta_{K D E L}{ }^{I B}$}

To independently assess myelin status in the brains of IBtreated $3 \times \mathrm{Tg}-\mathrm{AD}$ and Non-Tg mice, Black-Gold II staining was used (Figure 6, A-D). Quantitative analysis of the pixel intensity of myelin staining in the CA1 revealed restored levels in $3 \times \mathrm{Tg}-\mathrm{AD}$ mice intrahippocampally injected with rAAV-SCFVA $\beta_{\mathrm{KDEL}}{ }_{\mathrm{IB}}$ (Figure 6E), as compared with the rAAV-scFvphe ${ }_{\mathrm{KDEL}}{ }^{\mathrm{IB}}$-infused group. These analyses similarly demonstrated a rescue in the numbers of myelinated fibers in the CA1 hippocampal region of $3 \times \mathrm{Tg}-\mathrm{AD}$ mice injected with $\mathrm{rAAV}$-scFVA $\beta_{\mathrm{KDEL}} \mathrm{IB}$ (Figure 6F).

We additionally assessed the integrity of myelin sheaths of the Schaffer collateral fibers in the brains of $3 \times \mathrm{Tg}-\mathrm{AD}$ and Non-Tg mice injected with the IB-expressing rAAV2 vectors using electron microscopy. Previously, ultrastructural analysis of the myelin sheaths on the Schaffer collateral fibers of $3 \times \mathrm{Tg}-\mathrm{AD}$ mice exhibited significant disruptions in integrity by 6 months of age. ${ }^{5}$ The disrupted myelin sheaths include splitting of the major denseline and accumulation of dense bodies, indicative of age-related changes in myelin 
integrity. ${ }^{28}$ Our present results confirm a similar elevation in the percentage of compromised myelin sheaths in $3 \times$ Tg-AD mice injected with rAAV-scFvphe ${ }_{K D E L}{ }^{\mathrm{B}}$ as compared with Non-Tg mice injected with either rAAV vector (Figure 6, G-O). Importantly, 3×Tg-AD mice injected with rAAV-scFVA $\beta_{K D E L}{ }^{1 B}$ demonstrated signs of myelin sheath integrity restoration as compared with $\mathrm{rAAV}$-scFvphe ${ }_{\mathrm{KDEL}}{ }^{\mathrm{IB}_{-}}$ injected $3 \times \mathrm{Tg}-\mathrm{AD}$ mice. Collectively, these data further illustrate that the delivery of $\mathrm{rAAV}-\mathrm{SCFVA} \beta_{\mathrm{KDEL}}{ }^{\mathrm{IB}}$ to impede the accumulation of extracellular $A \beta_{1-42}$ effectively prevents myelin degeneration in the brains of $3 \times \mathrm{Tg}-\mathrm{AD}$ mice.

\section{Discussion}

Previous studies have uncovered normal age-related loss of myelin integrity at the ultrastructural level in humans and nonhuman primates. ${ }^{29,30}$ These alterations are exacerbated in AD brains, and the pathology is consistent with the detrimental effects inflicted by accumulating fibrillogenic $A \beta$ peptides. ${ }^{31}$ Song and colleagues observed white matter alterations in the brains of PDAPP mouse model of $A D$ using diffusion tensor imaging (DTI) with the manifestation of amyloid plaque pathology. ${ }^{32}$ Another study revealed decreased brain matter volume in the corpus callosum of PDAPP mice before the appearance of plaques. ${ }^{33}$ Gotz and colleagues discussed the presence of axonopathy and accumulation of both intracellular and extracellular $A \beta$ in white matter of Tg2576 mouse model. ${ }^{34}$ More importantly, Wirths et al detected myelin degeneration, myelin ovoid formation, and axonopathy in APP/PS1 double-transgenic mouse models correlative to intraneuronal $A \beta$ accumulation in the spinal cords to the mice. ${ }^{35}$ Our previous study indicated the appearance of compromised myelin sheaths enveloping Schaffer collateral axons of $3 \times \mathrm{Tg}-\mathrm{AD}$ mice in 6 month-old mice exhibiting intracellular $A \beta$ accumulation. ${ }^{5}$ In the present report, ultrastructural analyses of Schaffer collateral axons in the brains of $3 \times T$ Tg-AD mice intrahippocampally infused with rAAV-scFVA $\beta_{\text {KDEL }}{ }^{\text {IB }}$ demonstrated protection of myelin sheath integrity. The Schaffer collateral pathway is comprised of axons projecting from CA3 to CA1 and is integral to neurotransmission associated with learning and memory. ${ }^{36,37}$ Interestingly, others have shown that 6 month-old 3×Tg-AD mice exhibit defects in long-term potentiation (LTP) and long-term depression (LTD), two electrophysiological correlates of learning and memory. ${ }^{10}$ Another report revealed that the earliest cognitive defects manifest at 4 months of age in $3 \times \mathrm{Tg}-\mathrm{AD}$ mice leading to diminished long-term memory retention. ${ }^{12}$ Given the correlation between appearance of myelination defects and learning/memory deficits, it is possible that compromised myelin integrity contributes to diminishing cognitive function in early $\mathrm{AD}$. Additionally, early abnormalities in brain white matter might further contribute to the temporal and regional progression of axonopathy and classical pathogenesis of the disease.

Discriminating the individual contribution of $A \beta$-driven myelin degradation from direct $A \beta$-mediated effects on neurons during learning and memory formation in the $3 \times \mathrm{Tg}-\mathrm{AD}$ mouse model is a challenging endeavor. While our in vitro data indicate that $A \beta_{1-42}$ peptides in isolation can exact direct oligotoxic effects on immature and differentiated $\mathrm{mOP}$ cell cultures, the presence of human APPswe, PS1 $1^{\mathrm{M} 146 \mathrm{~V}}$, and tau ${ }^{\mathrm{P} 301 \mathrm{~L}}$ in the $3 \times \mathrm{Tg}-\mathrm{AD}$ mouse complicates, to some extent, dissection of the mechanism(s) underlying the susceptibility mechanism at play in vivo. The human APPswe and tau ${ }^{\mathrm{P} 301 \mathrm{~L}}$ transgenes are transcriptionally controlled by the neuron-specific mouse Thy 1.2 promoter, while the PS1 $1^{\mathrm{M} 146 \mathrm{~V}}$ mutation is "knocked-in" to the native mouse PS1 gene locus. The latter mutation, therefore, can be expressed in all cells supportive of the PS1 gene promoter, which includes cells of the oligodendrocyte lineage. ${ }^{38,39}$ This familial AD mutation has been shown to hypersensitize oligodendrocytes to various insults associated with $A D$, including $A \beta$ peptides. ${ }^{40}$ Hence, it is possible that the $A \beta$-induced changes in oligodendrocyte marker expression and myelin structure are at least partially mediated through oligodendrocyte-expressed PS1 ${ }^{\mathrm{M} 146 \mathrm{~V}}$. Isolation of each potential genetic player in single and double-transgenic $A D$ mice, as well as generation of conditional transgenics with oligodendrocyte-specific expression profiles, will help to differentiate "oligocentric" mechanisms from pathogenic signals indirectly derived from other $A \beta$-assaulted cell types.

Myelination requires a number of sequential steps in the maturation of the oligodendroglial cell lineage accompanied by a coordinated change in the expression of specific antigenic signatures. ${ }^{22}$ This unique feature of oligodendrocytes is often used to examine the disease-related effects on various developmental stages of the lineage. In the current study, we used antibodies specific for Olig2 (immature), CC-1 (mature), MBP (mature myelinating), and CNPase (pan-oligo marker) to assess the general composition of oligodendrocyte-related cells residing in the hippocampus of nonmanipulated and scFv-treated 3XTg-AD mice and control Non-Tg mice. Immunocytochemistry revealed that Olig2-positive immature oligodendrocyte numbers did not change as a function of age or ScFv treatment in 3XTg-AD mice. Similarly, the overall numbers of oligodendrocyte-related cells as determined by assessment of CNPase staining were unchanged after four months of ScFV expression. Interesting differences in oligodendrocyte profiles were revealed, however, when mature marker staining patterns were evaluated in rAAV vector-infused $3 \times \mathrm{Tg}-\mathrm{AD}$ mice. Oligodendrocytes expressing CC-1 were elevated, while those expressing MBP were decreased, in the CA1 hippocampal region of 6-month-old non-manipulated and rAAV-scFvphe KDEL $_{\text {IB }} 3 \times \mathrm{Tg}$-AD mice. These changes were effectively reversed and myelination integrity improved by intrahippocampal rAAV-scFVA $\beta_{\mathrm{KDEL}}{ }^{\mathrm{B}}$ infusion. Of note, previous reports have attributed CC-1 expression preferentially to nonmyelinating mature oligodendrocytes that lack MBP expression. ${ }^{41} \mathrm{CC}-1$ expression is localized to the cell body of mature oligodendrocytes, whereas MBP is found predominantly within cellular processes of myelinating oligodendrocytes, making assessment of CC-1/MBP doublepositive cells by immunocytochemistry technically difficult.

Our results suggest that $A \beta$ alters the composition of the mature oligodendrocyte pool and detrimentally affects myelin integrity. What we do not know at present is 
whether myelinating oligodendrocytes are more selectively vulnerable to $A \beta$ peptides in vivo. Mature myelinating oligodendrocytes are highly susceptible to oxidative stress due to their increased metabolic requirement and elevated iron and lipid content. It is possible that exposure to $A \beta$ disrupts the delicate homeostasis maintained in these cells, thereby leading to apoptotic cell death. ${ }^{42}$ Our in vitro experiments in immature and mature $\mathrm{mOP}$ cells did not reveal any stage-specific differences in $A \beta$ vulnerability. However, in vivo, where contributing factors relating to microglia-derived reactive oxygen species and cytokines, such as tumor necrosis factor- $\alpha$ (TNF- $\alpha$ ) are present, the selective impact on mature myelinating oligodendrocytes could be greater. In fact, Zeng and colleagues have shown that A $\beta$ enhances TNF- $\alpha$-mediated oligodendrocyte demise through a sphingomyelinase/ceramide pathway, ${ }^{43}$ while our laboratory has previously reported enhanced levels of TNF- $\alpha$ within the brains of $3 \times \mathrm{Tg}-\mathrm{AD}$ mice at ages identical to when oligodendrocyte/myelin deficits become evident.

Our current study does not directly address the contribution of the enzymes that are known classically to regulate neuronal hAPPswe processing to oligodendrocyte and myelin degeneration in $3 \times \mathrm{Tg}-\mathrm{AD}$ mice. $\beta$-site APP cleaving enzyme 1 (BACE1) is a key enzyme in the cleavage of APP and its neuronal activity is increased in AD. BACE1 cleavage is subsequently followed by an increase in $\gamma$-secretase activity, leading to the liberation of $A \beta$ peptides. ${ }^{44}$ Of note, BACE1 has been shown to be essential in the process of myelination and myelin repair through neuregulin signaling. ${ }^{45,46}$ Gamma-secretase activity has also been shown to be essential for neuregulin signaling involved in oligodendrocyte maturation. ${ }^{47}$ Another study reported that $\gamma$-secretase activity restricted the process of myelination, but the molecular mechanism involved in this effect remains unknown. ${ }^{48}$ Therefore, the possibility exists that the activities of these enzymes may contribute to the oligodendrocyte/myelin-related changes observed in young $3 \times \mathrm{Tg}-\mathrm{AD}$ mice. Further experimentation undoubtedly will be required to formally implicate oligodendrocyte-harbored BACE1 and/or $\gamma$-secretase in this process.

In summary, our study demonstrates pathogenic $A \beta$ mediated activity drives AD-related myelin injury in vivo. This phenomenon appears to result from impaired ability of mature oligodendrocytes to maintain/repair myelinated neuronal processes in response to $A \beta_{1-42}$ within the hippocampus of young $3 \times \mathrm{Tg}-\mathrm{AD}$ mice. These findings provide the rationale to explore the oligodendrocyte-resident signaling mechanisms lying downstream of $A \beta$ exposure, to determine whether $A \beta$ acts directly or indirectly on the oligodendrocyte lineage through neuronal and/or glial signals, to determine whether specific stages of oligodendrocyte differentiation are more or less susceptible to $A \beta$ or if $A \beta$ exposure alters the path of oligodendrocyte maturation, and to ultimately assess the consequences of these $A \beta$-mediated myelination defects on neurotransmission and hippocampal function. In aggregate, our studies provide further insights into the temporal and spatial progression of white matter disruption in the early presymptomatic stages of $A D$ and may illuminate new therapeutic strategies designed to avert these early impairments.

\section{Acknowledgments}

We thank Dr. Frank LaFerla (University of California, Irvine) for providing breeding pairs of $3 \times \mathrm{Tg}-\mathrm{AD}$ and Non-Tg mice, Karen L. de Mesy Bentley (University of Rochester) for electron microscopy services and advice, and Louis T. Lotta, Jr. (University of Rochester) for animal care and husbandry.

\section{References}

1. Dickerson BC, Sperling RA: Functional abnormalities of the medial temporal lobe memory system in mild cognitive impairment and Alzheimer's disease: insights from functional MRI studies. Neuropsychologia 2008, 46:1624-1635

2. de Leeuw FE, Barkhof F, Scheltens P: White matter lesions and hippocampal atrophy in Alzheimer's disease. Neurology 2004, 62:310-312

3. Roth AD, Ramirez G, Alarcon R, Von Bernhardi R: Oligodendrocytes damage in Alzheimer's disease: beta amyloid toxicity and inflammation. Biol Res 2005, 38:381-387

4. Roher AE, Weiss N, Kokjohn TA, Kuo YM, Kalback W, Anthony J, Watson D, Luehrs DC, Sue L, Walker D, Emmerling M, Goux W, Beach $\mathrm{T}$ : Increased A beta peptides and reduced cholesterol and myelin proteins characterize white matter degeneration in Alzheimer's disease. Biochemistry 2002, 41:11080-11090

5. Desai MK, Sudol KL, Janelsins MC, Mastrangelo MA, Frazer ME, Bowers WJ: Triple-transgenic Alzheimer's disease mice exhibit region-specific abnormalities in brain myelination patterns prior to appearance of amyloid and tau pathology. Glia 2009, 57:54-65

6. Villain N, Desgranges B, Viader F, de la Sayette V, Mezenge F, Landeau B, Baron JC, Eustache F, Chetelat G: Relationships between hippocampal atrophy, white matter disruption, and gray matter hypometabolism in Alzheimer's disease. J Neurosci 2008, 28:6174-6181

7. DeToledo-Morrell L, Stoub TR, Wang C: Hippocampal atrophy and disconnection in incipient and mild Alzheimer's disease. Prog Brain Res 2007, 163:741-753

8. Bartzokis G, Lu PH, Mintz J: Quantifying age-related myelin breakdown with MRI: novel therapeutic targets for preventing cognitive decline and Alzheimer's disease. J Alzheimers Dis 2004, 6:S53-59

9. Bartzokis G: Age-related myelin breakdown: a developmental model of cognitive decline and Alzheimer's disease, Neurobiol Aging 2004 , 25:5-18; author reply 49-62

10. Oddo S, Caccamo A, Shepherd JD, Murphy MP, Golde TE, Kayed R, Metherate R, Mattson MP, Akbari Y, LaFerla FM: Triple-transgenic model of Alzheimer's disease with plaques and tangles: intracellular $A \beta$ and synaptic dysfunction. Neuron 2003, 39:409-421

11. Mastrangelo MA, Bowers WJ: Detailed immunohistochemical characterization of temporal and spatial progression of Alzheimer's diseaserelated pathologies in male triple-transgenic mice. BMC Neurosci 2008, 9:81

12. Billings LM, Oddo S, Green KN, McGaugh JL, LaFerla FM: Intraneuronal Abeta causes the onset of early Alzheimer's disease-related cognitive deficits in transgenic mice. Neuron 2005, 45:675-688

13. Lee JT, Xu J, Lee JM, Ku G, Han X, Yang DI, Chen S, Hsu CY Amyloid-beta peptide induces oligodendrocyte death by activating the neutral sphingomyelinase-ceramide pathway. J Cell Biol 2004, 164:123-131

14. Xu J, Chen S, Ahmed SH, Chen H, Ku G, Goldberg MP, Hsu CY: Amyloid-beta peptides are cytotoxic to oligodendrocytes, J Neurosci 2001, 21:RC118

15. Jantaratnotai N, Ryu JK, Kim SU, McLarnon JG: Amyloid beta peptide-induced corpus callosum damage and glial activation in vivo. Neuroreport 2003, 14:1429-1433

16. Lin T, Xiang Z, Cui L, Stallcup W, Reeves SA: New mouse oligoden- 
drocyte precursor (mOP) cells for studies on oligodendrocyte maturation and function. J Neurosci Methods 2006, 157:187-194

17. Oddo S, Caccamo A, Kitazawa M, Tseng BP, LaFerla FM: Amyloid deposition precedes tangle formation in a triple transgenic model of Alzheimer's disease. Neurobiol Aging 2003, 24:1063-1070

18. Sudol KL, Mastrangelo MA, Narrow WC, Frazer ME, Levites YR, Golde TE, Federoff HJ, Bowers WJ: Generating differentially targeted amyloid-beta specific intrabodies as a passive vaccination strategy for Alzheimer's disease. Mol Ther 2009, 17:2031-2040

19. Malone J, Sullivan MA: Analysis of antibody selection by phage display utilizing anti- phenobarbital antibodies. J Mol Recognit 1996, 9:738-745

20. Urabe M, Nakakura T, Xin KQ, Obara Y, Mizukami H, Kume A, Kotin $\mathrm{RM}$, Ozawa K: Scalable generation of high-titer recombinant adenoassociated virus type 5 in insect cells. J Virol 2006, 80:1874-1885

21. Peterson EB, Mastrangelo MA, Federoff HJ, Bowers WJ: Neuronal specificity of HSV/sleeping beauty amplicon transduction in utero is driven primarily by tropism and cell type composition. Mol Ther 2007, 15:1848-1855

22. Baumann N, Pham-Dinh D: Biology of oligodendrocyte and myelin in the mammalian central nervous system. Physiol Rev 2001, 81:871-927

23. Su JH, Zhao M, Anderson AJ, Srinivasan A, Cotman CW: Activated caspase-3 expression in Alzheimer's and aged control brain: correlation with Alzheimer pathology. Brain Res 2001, 898:350-357

24. Rohn TT, Rissman RA, Head E, Cotman CW: Caspase activation in the Alzheimer's disease brain: tortuous and torturous. Drug News Perspect 2002, 15:549-557

25. Burger C, Gorbatyuk OS, Velardo MJ, Peden CS, Williams P, Zolotukhin S, Reier PJ, Mandel RJ, Muzyczka N: Recombinant AAV viral vectors pseudotyped with viral capsids from serotypes 1, 2, and 5 display differential efficiency and cell tropism after delivery to different regions of the central nervous system. Mol Ther 2004, 10:302-317

26. Hadaczek P, Kohutnicka M, Krauze MT, Bringas J, Pivirotto P, Cunningham J, Bankiewicz K: Convection-enhanced delivery of adenoassociated virus type 2 (AAV2) into the striatum and transport of AAV2 within monkey brain. Hum Gene Ther 2006, 17:291-302

27. Cunningham J, Oiwa Y, Nagy D, Podsakoff G, Colosi P, Bankiewicz KS: Distribution of AAV-TK following intracranial convection-enhanced delivery into rats. Cell Transplant 2000, 9:585-594

28. Hinman JD, Chen CD, Oh SY, Hollander W, Abraham CR: Agedependent accumulation of ubiquitinated 2', $3^{\prime}$-cyclic nucleotide $3^{\prime}$ phosphodiesterase in myelin lipid rafts. Glia 2008, 56:118-133

29. Wang DS, Bennett DA, Mufson EJ, Mattila P, Cochran E, Dickson DW: Contribution of changes in ubiquitin and myelin basic protein to age-related cognitive decline. Neurosci Res 2004, 48:93-100

30. Sloane JA, Hinman JD, Lubonia M, Hollander W, Abraham CR: Agedependent myelin degeneration and proteolysis of oligodendrocyte proteins is associated with the activation of calpain- 1 in the rhesus monkey. J Neurochem 2003, 84:157-168

31. Bartzokis G, Sultzer D, Lu PH, Nuechterlein KH, Mintz J, Cummings $\mathrm{JL}$ : Heterogeneous age-related breakdown of white matter structural integrity: implications for cortical "disconnection" in aging and Alzheimer's disease. Neurobiol Aging 2004, 25:843-851

32. Song SK, Kim JH, Lin SJ, Brendza RP, Holtzman DM: Diffusion tensor imaging detects age-dependent white matter changes in a transgenic mouse model with amyloid deposition. Neurobiol Dis 2004, 15:640-647
33. Redwine JM, Kosofsky B, Jacobs RE, Games D, Reilly JF, Morrison $\mathrm{JH}$, Young WG, Bloom FE: Dentate gyrus volume is reduced before onset of plaque formation in PDAPP mice: a magnetic resonance microscopy and stereologic analysis. Proc Natl Acad Sci USA 2003, 100:1381-1386

34. Gotz J, Ittner LM, Kins S: Do axonal defects in tau and amyloid precursor protein transgenic animals model axonopathy in Alzheimer's disease? J Neurochem 2006, 98:993-1006

35. Wirths O, Weis J, Szczygielski J, Multhaup G, Bayer TA: Axonopathy in an APP/PS1 transgenic mouse model of Alzheimer's disease. Acta Neuropathol 2006, 111:312-319

36. Steele PM, Mauk MD: Inhibitory control of LTP and LTD: stability of synapse strength. J Neurophysiol 1999, 81:1559-1566

37. Stanton PK: LTD. LTP, and the sliding threshold for long-term synaptic plasticity. Hippocampus 1996, 6:35-42

38. Pak KJ, Chan SL, Mattson MP: Homocysteine and folate deficiency sensitize oligodendrocytes to the cell death-promoting effects of a presenilin-1 mutation and amyloid beta-peptide. Neuromolecular Med 2003, 3:119-128

39. Guo Q, Sebastian L, Sopher BL, Miller MW, Ware CB, Martin GM, Mattson MP: Increased vulnerability of hippocampal neurons from presenilin-1 mutant knock-in mice to amyloid beta-peptide toxicity: central roles of superoxide production and caspase activation. J Neurochem 1999, 72:1019-1029

40. Pak K, Chan SL, Mattson MP: Presenilin-1 mutation sensitizes oligodendrocytes to glutamate and amyloid toxicities, and exacerbates white matter damage and memory impairment in mice. Neuromolecular Med 2003, 3:53-64

41. Mela A, Goldman JE: The tetraspanin KAI1/CD82 is expressed by late-lineage oligodendrocyte precursors and may function to restrict precursor migration and promote oligodendrocyte differentiation and myelination. J Neurosci 2009, 29:11172-11181

42. Butts BD, Houde C, Mehmet H: Maturation-dependent sensitivity of oligodendrocyte lineage cells to apoptosis: implications for normal development and disease. Cell Death Differ 2008, 15:1178-1186

43. Zeng C, Lee JT, Chen H, Chen S, Hsu CY, Xu J: Amyloid-beta peptide enhances tumor necrosis factor-alpha-induced iNOS through neutral sphingomyelinase/ceramide pathway in oligodendrocytes. J Neurochem 2005, 94:703-712

44. Laird FM, Cai H, Savonenko AV, Farah MH, He K, Melnikova T, Wen $\mathrm{H}$, Chiang HC, Xu G, Koliatsos VE, Borchelt DR, Price DL, Lee HK, Wong PC: BACE1, a major determinant of selective vulnerability of the brain to amyloid-beta amyloidogenesis, is essential for cognitive, emotional, and synaptic functions. J Neurosci 2005, 25:11693-11709

45. Hu X, Hicks CW, He W, Wong P, Macklin WB, Trapp BD, Yan R: Bace1 modulates myelination in the central and peripheral nervous system. Nat Neurosci 2006, 9:1520-1525

46. Wang $H$, Song L, Laird F, Wong PC, Lee HK: BACE1 knock-outs display deficits in activity-dependent potentiation of synaptic transmission at mossy fiber to CA3 synapses in the hippocampus. J Neurosci 2008, 28:8677-8681

47. Lai C, Feng L: Implication of gamma-secretase in neuregulin-induced maturation of oligodendrocytes. Biochem Biophys Res Commun 2004, 314:535-542

48. Watkins TA, Emery B, Mulinyawe S, Barres BA: Distinct stages of myelination regulated by gamma-secretase and astrocytes in a rapidly myelinating CNS coculture system. Neuron 2008, 60:555-569 